\title{
Temperature data acquired from the DOI/GTN-P Deep Borehole Array on the Arctic Slope of Alaska, 1973-2013
}

\author{
G. D. Clow \\ US Geological Survey, Boulder, Colorado, USA \\ Correspondence to: G. D. Clow (clow@usgs.gov)
}

\begin{abstract}
Received: 3 December 2013 - Published in Earth Syst. Sci. Data Discuss.: 20 January 2014
\end{abstract}
Revised: 16 April 2014 - Accepted: 17 April 2014 - Published: 23 May 2014

\begin{abstract}
A homogeneous set of temperature measurements obtained from the DOI/GTN-P Deep Borehole Array between 1973 and 2013 is presented; DOI/GTN-P is the US Department of the Interior contribution to the Global Terrestrial Network for Permafrost (GTN-P). The 23-element array is located on the Arctic Slope of Alaska, a region of cold continuous permafrost. Most of the monitoring wells are situated on the Arctic coastal plain between the Brooks Range and the Arctic Ocean, while others are in the foothills to the south. The data represent the true temperatures in the wellbores and surrounding rocks at the time of the measurements; they have not been corrected to remove the thermal disturbance caused by drilling the wells. With a few exceptions, the drilling disturbance is estimated to have been on the order of $0.1 \mathrm{~K}$ or less by 1989 . Thus, most of the temperature measurements acquired during the last $25 \mathrm{yr}$ are little affected by the drilling disturbance. The data contribute to ongoing efforts to monitor changes in the thermal state of permafrost in both hemispheres by the Global Terrestrial Network for Permafrost, one of the primary subnetworks of the Global Terrestrial Observing System (GTOS). The data will also be useful for refining our basic understanding of the physical conditions in permafrost in Arctic Alaska, as well as providing important information for validating predictive models used for climate impact assessments. The processed data are available from the Advanced Cooperative Arctic Data and Information Service (ACADIS) repository at doi:10.5065/D6N014HK.
\end{abstract}

\section{Introduction}

The Arctic is highly sensitive to increases in global mean air temperature as exemplified by the large and persistent physical and biological changes currently being observed there (Jeffries et al., 2012, 2013). In turn, the Arctic can have a significant impact on the global climate system through icealbedo feedbacks and the potential loss of vast amounts of methane (a potent greenhouse gas) stored in permafrost to the atmosphere. Despite this, the Arctic remains a data-sparse region, limiting our understanding of critical processes and our ability to project future environmental conditions. To address this issue, several initiatives have been undertaken to develop comprehensive observing systems for the atmosphere, ocean, and terrestrial components of the Arctic climate system (e.g, the Sustaining Arctic Observing Networks initiative). These observing systems are generally built from an aggregation of many national or regional observing networks. The success of these comprehensive observing systems critically depends on the contributions from the individual networks.

Here we focus on one such network designed to monitor the thermal state of permafrost on the Arctic Slope of Alaska. The origin of the network began $40 \mathrm{yr}$ ago. From 1975 to 1981, 28 test wells were drilled in the National Petroleum Reserve-Alaska (NPR-A) as part of a petroleum exploration program overseen by the US Department of the Interior (Gryc, 1988). These 1-6 km deep wells (Fig. 1) penetrated marine and nonmarine sedimentary sequences between the Brooks Range and the Arctic Ocean. Most of the well sites are on the low-lying Arctic coastal plain while a few are in the rolling foothills to the south. Permafrost in this area is "continuous", being $200-400 \mathrm{~m}$ thick. As with all deep wells, temperatures in the wellbores and surrounding rocks were significantly disturbed by the addition of drilling muds, circulating fluids, and other processes during drilling. This thermal drilling disturbance eventually dissipates over 


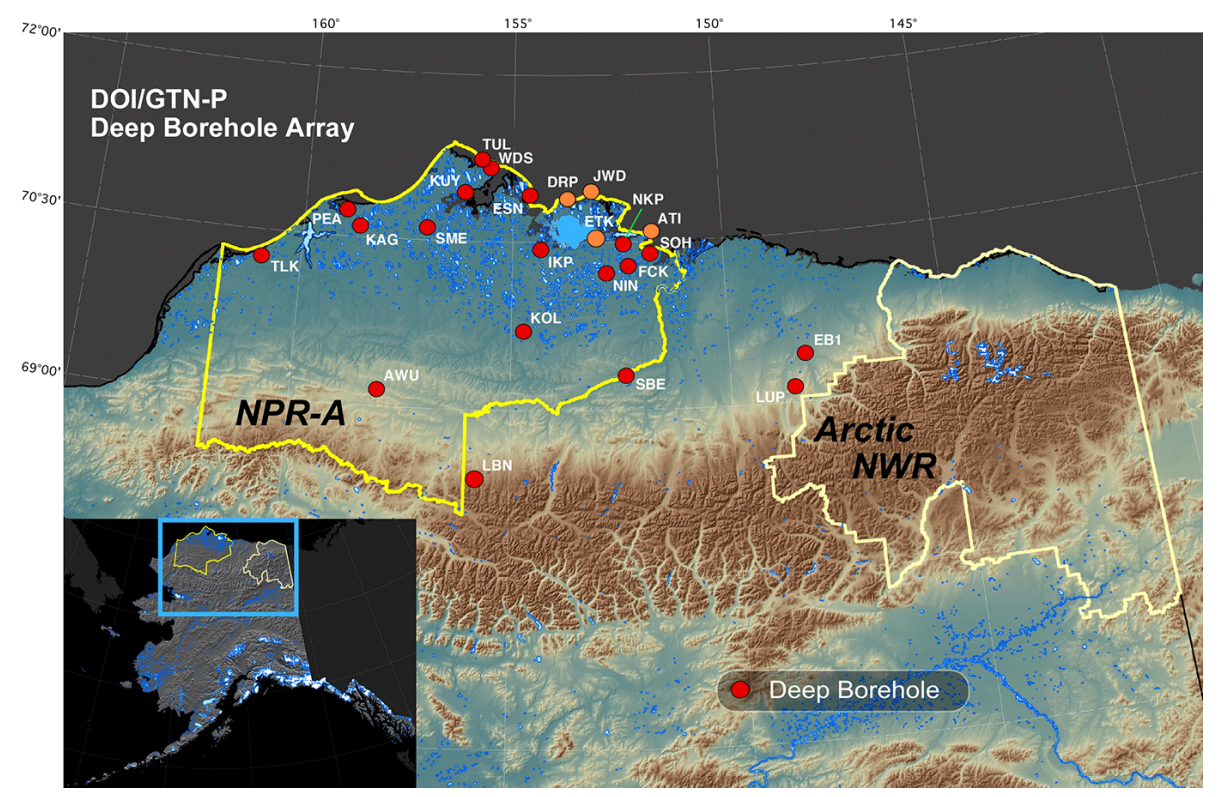

Figure 1. Location of the $23 \mathrm{DOI} / \mathrm{GTN}-\mathrm{P}$ boreholes used to monitor the thermal state of permafrost (TSP) in the National Petroleum Reserve-Alaska (NPR-A) and near the Arctic National Wildlife Refuge. Wells indicated by orange symbols have been plugged and are no longer accessible.

many years (Lachenbruch and Brewer, 1959). Wells drilled by the petroleum industry on the Arctic Slope of Alaska were almost always either put into production or plugged and abandoned long before the wells could return to thermal equilibrium. Realizing that the NPR-A test wells provided a rare opportunity to obtain "undisturbed" temperatures in permafrost, the US Geological Survey (USGS) requested that 21 of the wells (Table 1) be completed in a manner that would allow high-precision temperature measurements to be made over many years. This involved filling the borehole casing with a nonfreezing fluid (diesel oil) above a cement plug installed 200-900 m below the surface, depending on the well. Four other wells to the east were preserved in a similar manner through the courtesy of Mobil, Exxon, BP, Sinclair, and Forest oil companies. Information obtained from the borehole temperature measurements was expected to provide better estimates of the regional permafrost thickness and of the physical conditions controlling the occurrence of ice, unfrozen water, and gas hydrates in permafrost than was currently available.

After monitoring temperatures in these wells for several years, it became clear that the temperature profiles also contained evidence of recent climate change in Arctic Alaska. The theory behind this climate-change effect is that any change in the surface energy balance would generate a downward-propagating thermal wave. Without the disruptive effects of groundwater flow, this thermal wave is effectively preserved in cold continuous permafrost, although the magnitude of the signal dissipates over time. With sufficiently sensitive instruments, a climate-induced thermal

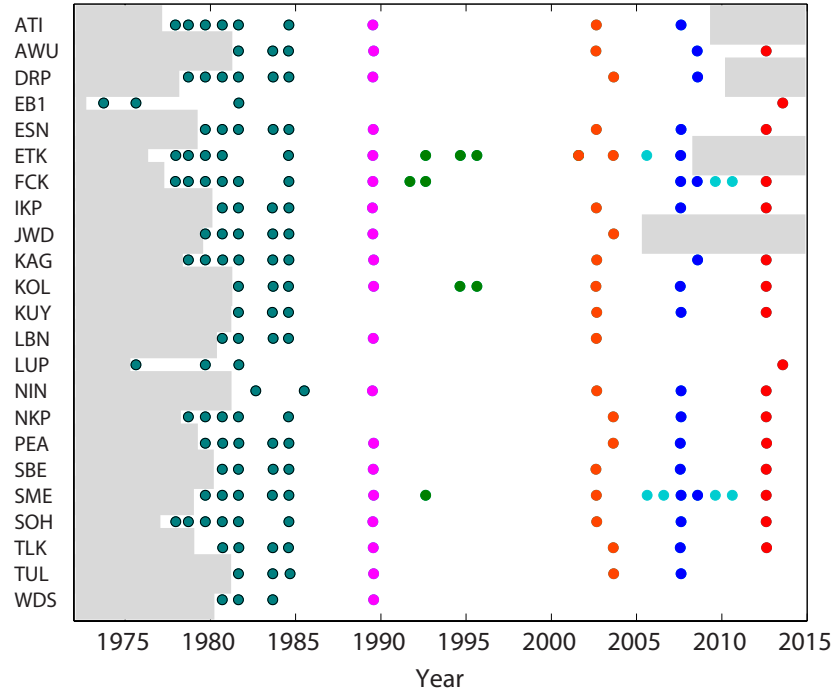

Figure 2. Temperature logging history for the DOI/GTN-P Deep Borehole Array. Major field campaigns occurred during 1977-1984 (teal), 1989 (magenta), 2002-2003 (orange-red), 2007-2008 (blue), and 2012-2013 (red). Gray areas indicate times before well completion, and in some instances when the wells have been plugged and abandoned due to coastal erosion issues.

wave could be detected and the associated change in surface temperature inferred. Using this idea and temperatures from the NPR-A monitoring wells and from the nearby Prudhoe Bay oil field, Lachenbruch published a series of papers in the 1980s (Lachenbruch et al., 1982, 1988b; Lachenbruch and Marshall, 1986) in which he inferred surface temperatures in 
Table 1. USGS and GTN-P well codes, location, maximum accessible depth, and date of first temperature log for the DOI/GTN-P monitoring wells. Boreholes coupled with a nearby DOI/GTN-P climate station are indicated.

\begin{tabular}{|c|c|c|c|c|c|c|c|}
\hline Borehole & $\begin{array}{l}\text { USGS } \\
\text { code }\end{array}$ & $\begin{array}{l}\text { GTN-P } \\
\text { code }\end{array}$ & $\begin{array}{l}\text { Latitude } \\
\text { (north) }\end{array}$ & $\begin{array}{l}\text { Longitude } \\
\text { (west) }\end{array}$ & $\begin{array}{l}\text { Depth } \\
\text { (m) }\end{array}$ & $\begin{array}{l}\text { First log } \\
\text { (day-mon-yr) }\end{array}$ & $\begin{array}{l}\text { Climate } \\
\text { station }\end{array}$ \\
\hline Atigaru Test Well No. 1 & ATI & US 01 & $70^{\circ} 33.348^{\prime}$ & $151^{\circ} 43.229^{\prime}$ & 648 & 14 Dec 1977 & \\
\hline Awuna Test Well No. 1 & AWU & US 02 & $69^{\circ} 09.193^{\prime}$ & $158^{\circ} 01.355^{\prime}$ & 884 & 22 Aug 1981 & - \\
\hline Drew Point Test Well No. 1 & DRP & US 03 & $70^{\circ} 52.762^{\prime}$ & $153^{\circ} 54.202^{\prime}$ & 640 & 17 Sep 1978 & - \\
\hline East Simpson Test Well No. 1 & ESN & US 04 & $70^{\circ} 55.046^{\prime}$ & $154^{\circ} 37.286^{\prime}$ & 600 & 13 Sep 1979 & \\
\hline East Teshekpuk Test Well No. 1 & ETK & US 05 & $70^{\circ} 34.171^{\prime}$ & $152^{\circ} 56.815^{\prime}$ & 727 & 17 Dec 1977 & - \\
\hline Echooka Unit No. 1 & EB1 & US 93 & $69^{\circ} 23.994^{\prime}$ & $148^{\circ} 16.313^{\prime}$ & 595 & 26 Sep 1973 & \\
\hline Ikpikpuk Test Well No. 1 & IKP & US 07 & $70^{\circ} 27.305^{\prime}$ & $154^{\circ} 20.082^{\prime}$ & 615 & 10 Sep 1980 & - \\
\hline J. W. Dalton Test Well No. 1 & JWD & US 08 & $70^{\circ} 55.207^{\prime}$ & $153^{\circ} 08.454^{\prime}$ & 483 & 13 Sep 1979 & \\
\hline Koluktak Test Well No. 1 & KOL & US 10 & $69^{\circ} 45.144^{\prime}$ & $154^{\circ} 36.669^{\prime}$ & 227 & 23 Aug 1981 & - \\
\hline Kugrua Test Well No. 1 & KAG & US 09 & $70^{\circ} 35.191^{\prime}$ & $158^{\circ} 39.923^{\prime}$ & 582 & 15 Sep 1978 & \\
\hline Kuyanak Test Well No. 1 & KUY & US 11 & $70^{\circ} 55.869^{\prime}$ & $156^{\circ} 04.092^{\prime}$ & 856 & 25 Aug 1981 & \\
\hline Lisburne Test Well No. 1 & LBN & US 12 & $68^{\circ} 29.061^{\prime}$ & $155^{\circ} 41.773^{\prime}$ & 532 & 9 Sep 1980 & \\
\hline Lupine Unit No. 1 & LUP & US 92 & $69^{\circ} 06.051^{\prime}$ & $148^{\circ} 37.290^{\prime}$ & 469 & 15 Aug 1975 & \\
\hline North Inigok Test Well No. 1 & NIN & US 13 & $70^{\circ} 15.435^{\prime}$ & $152^{\circ} 46.139^{\prime}$ & 625 & 31 Aug 1982 & \\
\hline North Kalikpik Test Well No. 1 & NKP & US 14 & $70^{\circ} 30.550^{\prime}$ & $152^{\circ} 22.070^{\prime}$ & 660 & 16 Sep 1978 & \\
\hline Peard Bay Test Well No. 1 & PEA & US 15 & $70^{\circ} 42.939^{\prime}$ & $159^{\circ} 00.042^{\prime}$ & 591 & 15 Sep 1979 & \\
\hline Seabee Test Well No. 1 & SBE & US 16 & $69^{\circ} 22.809^{\prime}$ & $152^{\circ} 10.522^{\prime}$ & 393 & 9 Sep 1980 & - \\
\hline South Harrison Test Well No. 1 & $\mathrm{SOH}$ & US 18 & $70^{\circ} 25.468^{\prime}$ & $151^{\circ} 44.071^{\prime}$ & 399 & 16 Dec 1977 & \\
\hline South Meade Test Well No. 1 & SME & US 17 & $70^{\circ} 36.872^{\prime}$ & $156^{\circ} 53.601^{\prime}$ & 549 & 14 Sep 1979 & - \\
\hline Tulageak Test Well No. 1 & TUL & US 20 & $71^{\circ} 11.338^{\prime}$ & $155^{\circ} 44.228^{\prime}$ & 756 & 24 Aug 1981 & \\
\hline Tunalik Test Well No. 1 & TLK & US 19 & $70^{\circ} 12.358^{\prime}$ & $161^{\circ} 04.153^{\prime}$ & 556 & 15 Sep 1980 & - \\
\hline West Dease Test Well No. 1 & WDS & US 21 & $71^{\circ} 09.524^{\prime}$ & $155^{\circ} 37.983^{\prime}$ & 823 & 14 Sep 1980 & \\
\hline West Fish Creek Test Well No. 1 & FCK & US 06 & $70^{\circ} 19.600^{\prime}$ & $152^{\circ} 03.634^{\prime}$ & 735 & 11 Dec 1977 & - \\
\hline
\end{tabular}

the Alaskan Arctic had warmed 2-4 K since 1900. Given the paucity of long-term instrumental records in the Arctic documenting recent climate change, Lachenbruch's work was particularly important. Soon thereafter, other researchers began to use subsurface permafrost temperatures to document recent climate changes in the North American Arctic (e.g. Nielsen and Beck, 1989; Mareschal and Beltrami, 1992; Beltrami and Mareschal, 1992; Osterkamp and Romanovsky, 1999; Smith et al., 2005; Osterkamp and Jorgenson, 2006; Taylor et al., 2006; Smith et al., 2010; Romanovsky et al., 2010).

In 1999, the 21 NPR-A temperature-monitoring wells were incorporated into the Global Terrestrial Network for Permafrost (GTN-P), a new component of the Global Climate Observing System (GCOS) and one of its primary subnetworks, the Global Terrestrial Observing System (GTOS). This formalized the use of the borehole array for monitoring the thermal state of permafrost (TSP), one of the Essential Climate Variables (ECVs) tracked by the global climate observing systems (Sessa and Dolman, 2008; Smith and Brown, 2009). Upon inclusion into GTN-P, the NPR-A wells became the largest array of deep $(>125 \mathrm{~m})$ boreholes in the world used for monitoring temperatures in permafrost (IPA, 2010). The array is unique in that it also provides one the longest records of permafrost thermal state. As management of the array was shared by two US Department of the Interior (DOI)

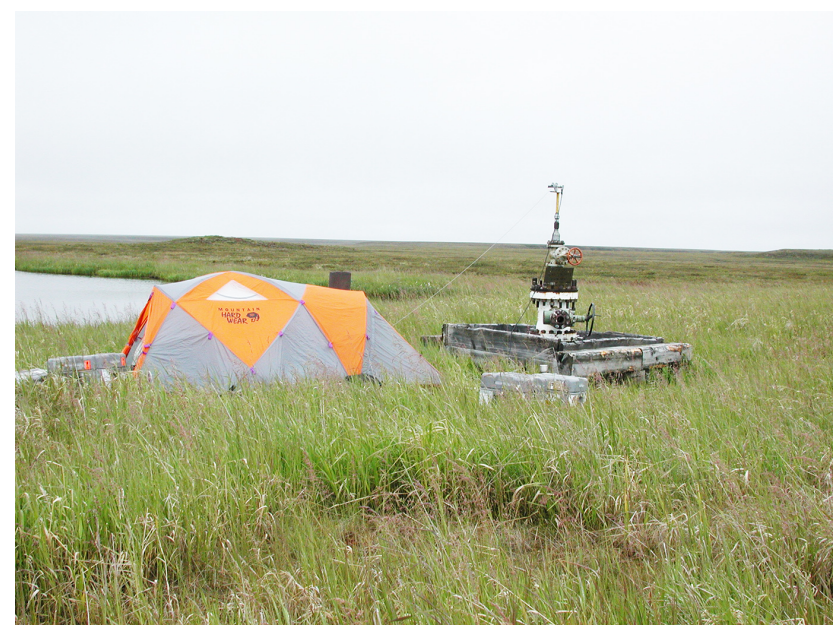

Figure 3. Measuring temperatures in the Koluktak (KOL) Test Well No. 1, National Petroleum Reserve-Alaska. This well is typical of the other wells in the DOI/GTN-P Deep Borehole Array.

agencies (USGS and the Bureau of Land Management), the array became known as the DOI/GTN-P Deep Borehole Array. Two of the four wells that had been preserved for USGS temperature monitoring to the east of the NPR-A (Lupine and Echooka, Fig. 1, Table 1) were later incorporated into 


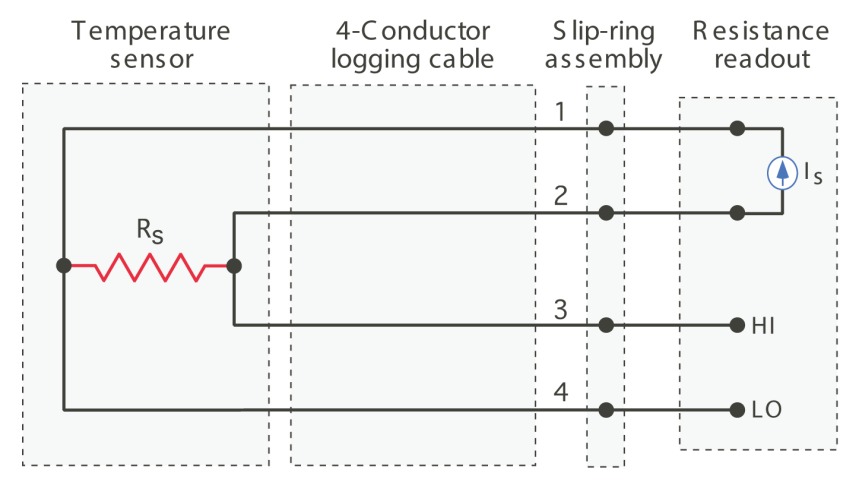

Figure 4. Kelvin (4-wire) resistance circuit used by the USGS portable logging system. The test current $I_{\mathrm{S}}$ passes through lines 1 and 2, while the voltage drop across the probe resistance $R_{\mathrm{S}}$ is measured using the sense lines $(3,4)$. Logging cables used with the portable system are $450-900 \mathrm{~m}$ long. The resistance readout is located on the surface.

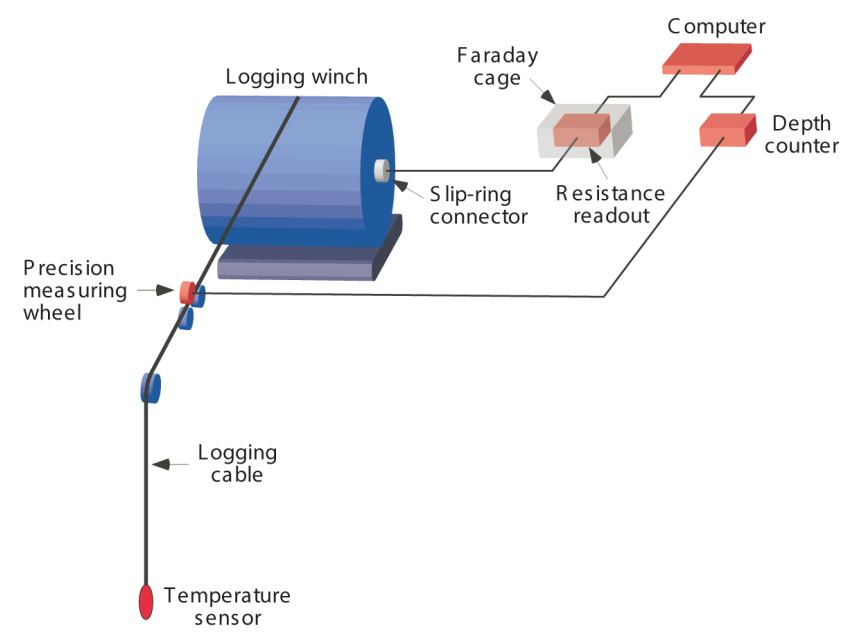

Figure 5. Layout of the post-1999 version of the USGS portable temperature logging system used in Arctic Alaska.

GTN-P, bringing the total number of wells in the DOI/GTNP Deep Borehole Array to 23. Beginning in 1998, USGS also began deploying automated climate-monitoring stations in the NPR-A to better understand the nature of the recent permafrost warming observed there. Nine of the climate stations were collocated with DOI/GTN-P boreholes to form "permafrost observatories" (Table 1), although two of the boreholes were subsequently plugged and abandoned due to the threat of coastal erosion. Data from the DOI/GTN-P climate stations are available from Urban and Clow (2014).

Here we present the temperature data acquired from the DOI/GTN-P Deep Borehole Array in Arctic Alaska over the $40 \mathrm{yr}$ period, 1973-2013. The data represent the true temperatures in the wellbores and surrounding rocks at the time of the measurements; they have not been "corrected" to remove the thermal disturbance caused by drilling the wells. For the great majority of wells, the drilling disturbance is estimated to have been on the order of $0.1 \mathrm{~K}$ or less by 1989 . Thus, most of the temperature measurements acquired over the last $25 \mathrm{yr}$ are little affected by the drilling disturbance. The data set presented here is intended to serve as the reference point from which data sets corrected for the drilling disturbance will be derived, enhancing the usefulness of the earlier temperature logs. In addition, analysis of the uncorrected temperature logs can provide important information about the ice and unfrozen water content in the permafrost zone. As shown in Fig. 2, temperature measurements in the DOI/GTN-P monitoring wells were concentrated during distinct field campaigns that occurred during 1977-1984, 1989, 2002-2003, 2007-2008, and 2012-2013. Measurements were curtailed during the 1990s due to funding limitations, except for a few experimental logs designed to test design changes in the temperature logging system. Measurements were resumed in 2002 under a GTN-P protocol specifying that contributing deep borehole arrays be resampled every $5 \mathrm{yr}$ (Fig. 3). By 2010, four of the monitoring wells (ATI, DRP, ETK, JWD) had been plugged and abandoned due to coastal erosion and were no longer accessible. Data from the DOI/GTN-P Deep Borehole Array will be useful for documenting how the thermal state of permafrost is changing on the Arctic Slope of Alaska in response to climate change. Given the important role that permafrost has in shaping the regional landscape, this information is critical for understanding how lakeshore, river, and coastal environments may change in the near future; anticipating impacts on terrestrial ecosystem habitats; and for making well-informed land management decisions in the face of rapid climate change. The data will also be useful for refining our basic understanding of the physical conditions occurring within permafrost in this region.

\section{Instruments and methods}

\subsection{Borehole temperature measurements}

The "portable" logging system used by the US Geological Survey to measure temperatures in the DOI/GTN-P boreholes consists of a custom temperature sensor whose resistance is determined by a resistance readout (digital multimeter) using a 4-wire Kelvin circuit. This circuit effectively compensates for the resistance of the logging cable and various connectors that provide the electrical path between the downhole temperature sensor and the resistance readout located on the surface (Fig. 4). The temperature sensor consists of a parallel-series network of negative-temperaturecoefficient (NTC) thermistors hermitically sealed in glass. These in turn are enclosed in a thin (4 mm diameter) stainless steel shell to isolate the thermistors from pressure effects and corrosive chemicals. The resulting probe design has proved to be rugged and stable, and provides a high temperature sensitivity (Sass et al., 1971; Clow, 2008).

Several refinements have been made to the portable system since the 1970s, when measurements began in the 

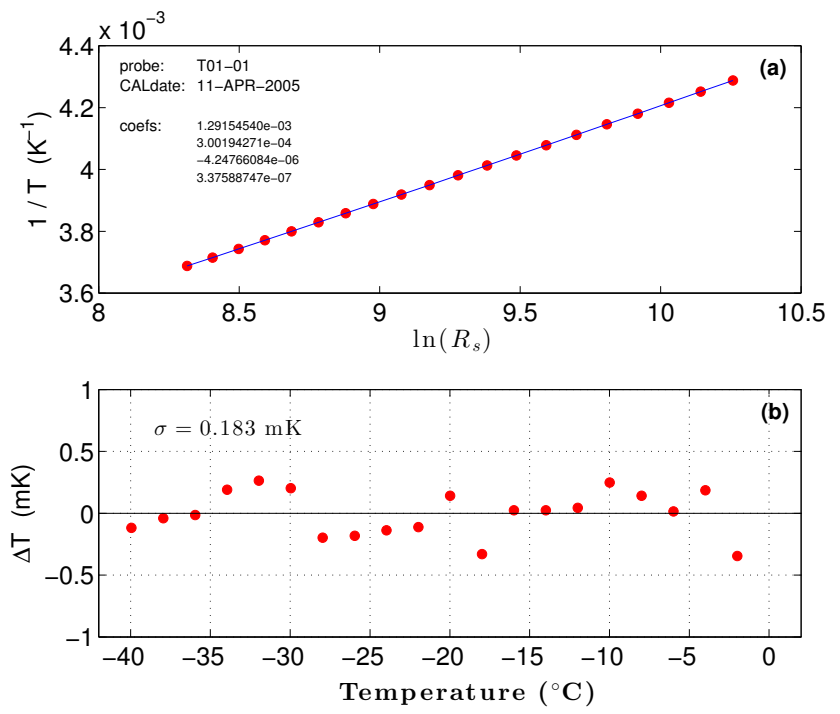

Figure 6. Sample calibration data over the range -40 to $-2{ }^{\circ} \mathrm{C}$ for one of the USGS temperature sensors (T01-01) along with the best-fit 4-term calibration function (a). Panel (b) shows the residuals from the calibration fit. In this example, the standard deviation of the calibration residuals is $0.183 \mathrm{mK}$.

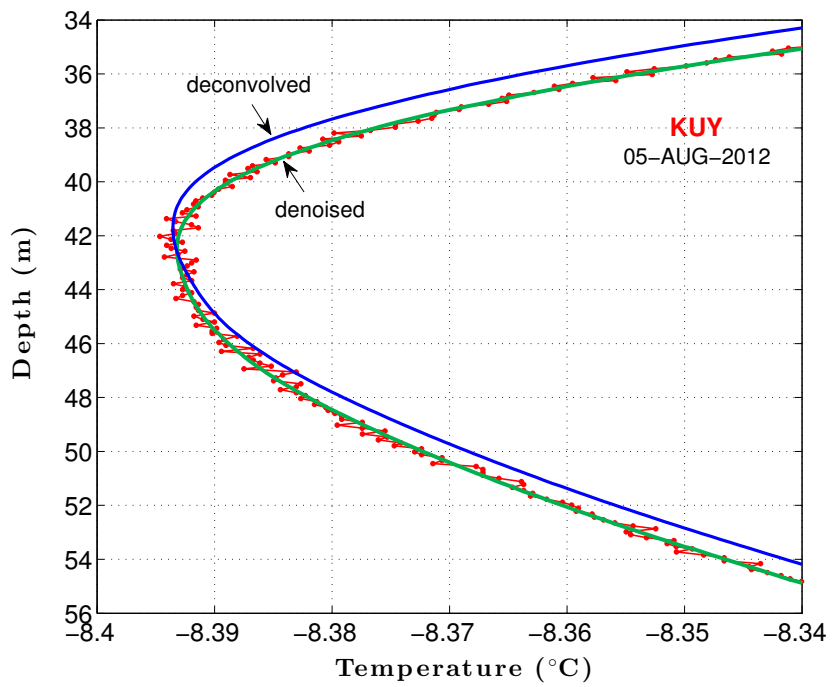

Figure 7. Portion of a sample DOI/GTN-P temperature log (Kuyanak Test Well No. 1, 5 August 2012). The temperature measurements $\mathcal{T}$ are shown in red, while the denoised signal is given by the green line. Blue line shows the deconvolved signal, which represents the actual temperatures $T$ in the borehole taking into account the response time of the moving probe.
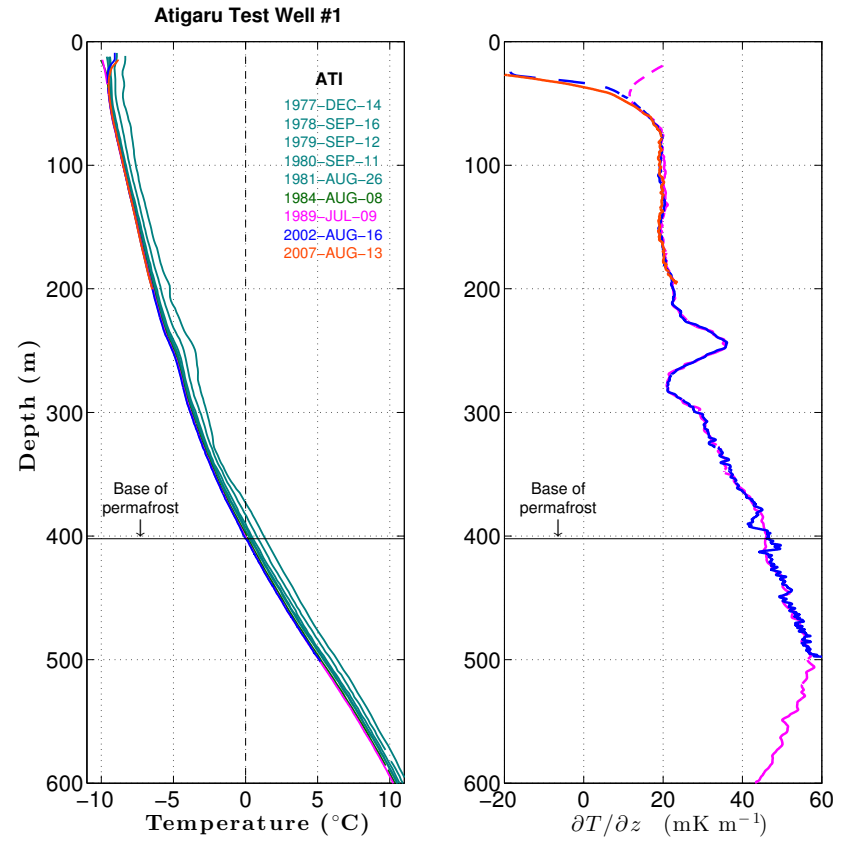

Figure 8. Temperature profiles in the Atigaru Test Well No. 1, color-coded by acquisition date (left). Due to the dissipation of the drilling disturbance, the temperature profiles cool progressively over time. Thus, the first log (1977-DEC-14) is the warmest of the series. Temperature gradients calculated from the 1989, 2002, and 2007 logs are shown in the right panel using the same color coding. Black horizontal line shows the base of permafrost.
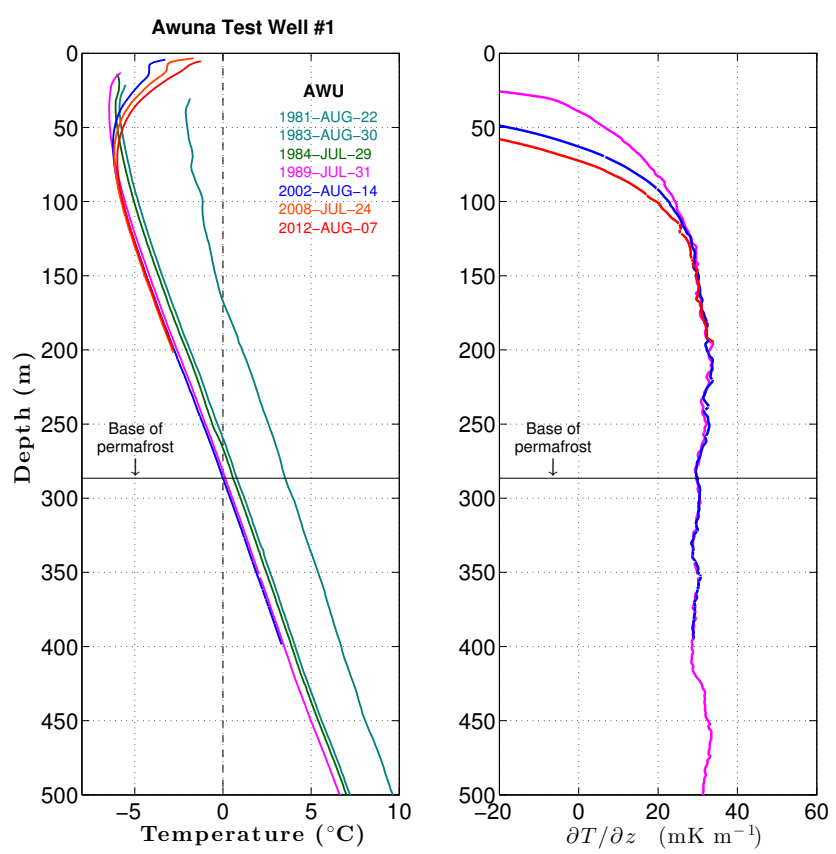

Figure 9. Temperature profiles in the Awuna Test Well No. 1, colorcoded by acquisition date (left). Temperature gradients calculated from the 1989, 2002, and $2012 \operatorname{logs}$ are shown in the right panel. 
DOI/GTN-P boreholes. To minimize weight, the early version of the system did not have a slip-ring assembly. Temperatures were measured at fixed depths, typically every 1.5 or $3.0 \mathrm{~m}$, and the logging cable disconnected from the resistance readout when moving from one measurement depth to the next. At each depth, measurements were made until the sensor approached thermal equilibrium with the surrounding environment. A high-quality slip-ring connector was introduced to the system in 1984, allowing measurements to be acquired while the sensor was moving continuously downhole; a circuit triggered the system to acquire a measurement every $30 \mathrm{~cm}$. The depth and sensor resistance measurements were automatically recorded on magnetic tape. A logging speed of $\sim 10 \mathrm{~cm} \mathrm{~s}^{-1}$ was used with this system.

One disadvantage of the rugged probe design is the relatively slow response time ( $\tau \in 7-15 \mathrm{~s})$. Given the thermal memory of the probe, a time deconvolution is required to determine the actual temperature at any given depth from the temperature measurements while the sensor is moving. To assist with the deconvolution, the resistance readout was upgraded in 1991, enabling measurements to be triggered on even time increments (every $2 \mathrm{~s}$ ) while a computer provided the time of each triggering event. The primary data stream then consisted of time, depth, and sensor resistance. The logging speed was also reduced to $2.5-5 \mathrm{~cm} \mathrm{~s}^{-1}$ to reduce the magnitude of the deconvolution correction. With a triggering rate of $2 \mathrm{~s}$, this decreased the depth interval between measurements to $5-10 \mathrm{~cm}$. An additional change aimed at improving the results of the time deconvolution was to replace the hydraulic clutch that regulated the probe descent with a motor drive to reduce variations in the probe's downhole speed. The new resistance readout also offered 10 times the resolution while simultaneously reducing the test current $I_{\mathrm{s}}$ by a factor of 10 . The latter feature reduced the heating of the thermistor beads during a measurement due to the test current by $10^{2}$. Utilizing another capability of the new readout, the measuring circuit was recalibrated before each temperature $\log$ using a set of "standard" resistors.

Efforts were made through the 1990s to further reduce the uncertainty of the resistance measurements. Issues that were addressed included drift of the measurement circuitry due to environmental changes during a log and spurious electrical noise caused by the winch motor, the presence of the system operator, blowing snow, and other sources. By 1999, these issues were effectively resolved by locating the resistance readout in a Faraday cage maintained at $23 \pm 0.5^{\circ} \mathrm{C}$ for the duration of a logging experiment. The system has changed little since that time. A complete description of the current system (Fig. 5) and the associated measurement uncertainties is given by Clow (2008). Although a complete uncertainty analysis was not done for the early version of the portable system, Sass et al. (1971) and Lachenbruch et al. (1988a) state that the precision of the measurements was better than $0.01 \mathrm{~K}$ while the absolute accuracy was "probably only a few hundredths of a degree". This level of uncertainty
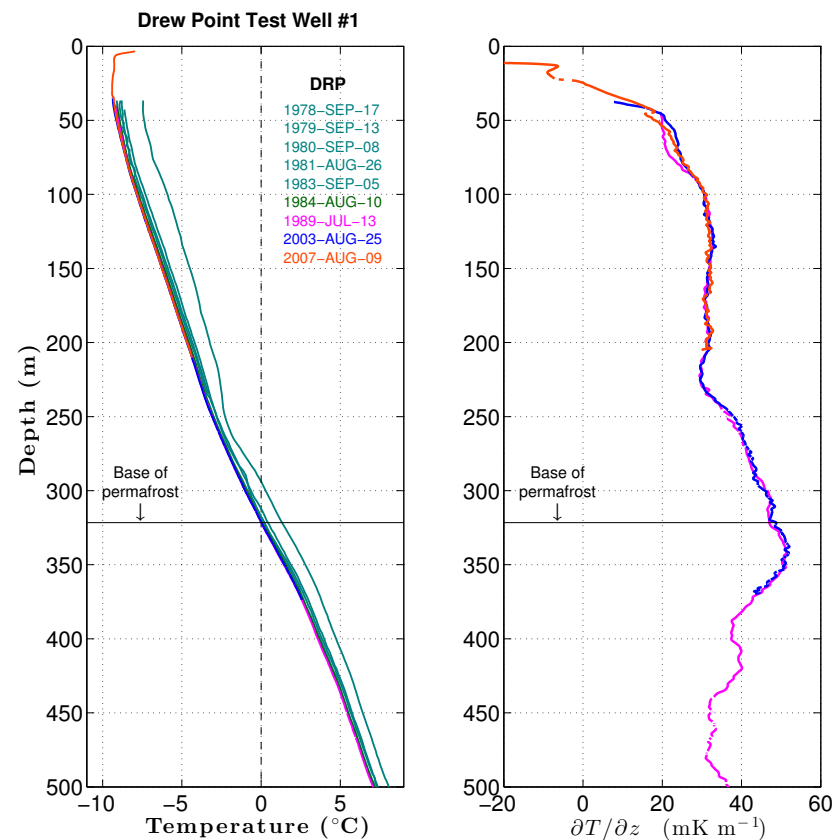

Figure 10. Temperature profiles in the Drew Point Test Well No. 1, color-coded by acquisition date (left). Temperature gradients calculated from the 1989, 2003, and $2007 \operatorname{logs}$ are shown in the right panel.
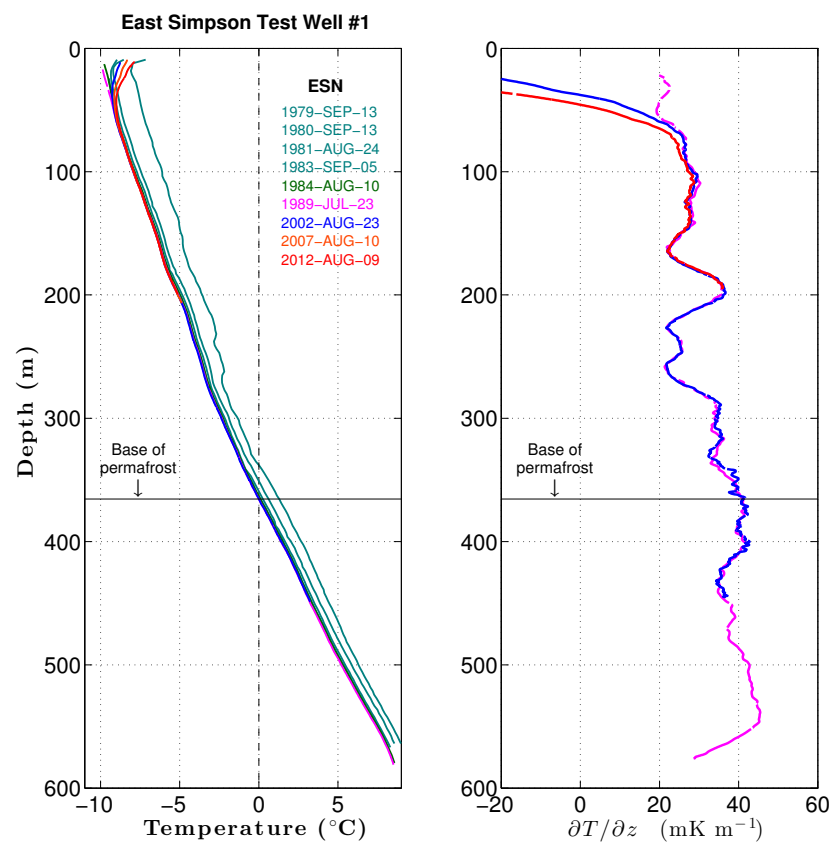

Figure 11. Temperature profiles in the East Simpson Test Well No. 1, color-coded by acquisition date (left). Temperature gradients calculated from the 1989, 2002, and 2012 logs are shown in the right panel. 

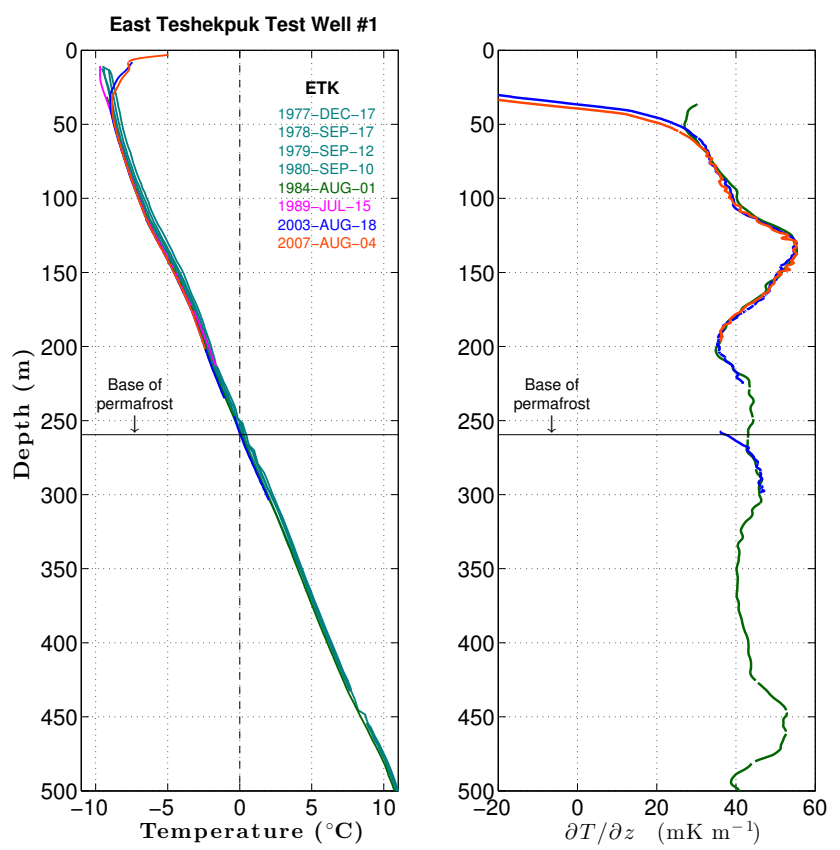

Figure 12. Temperature profiles in the East Teshekpuk Test Well No. 1, color-coded by acquisition date (left). Temperature gradients calculated from the 1984, 2003, and $2007 \operatorname{logs}$ are shown in the right panel.
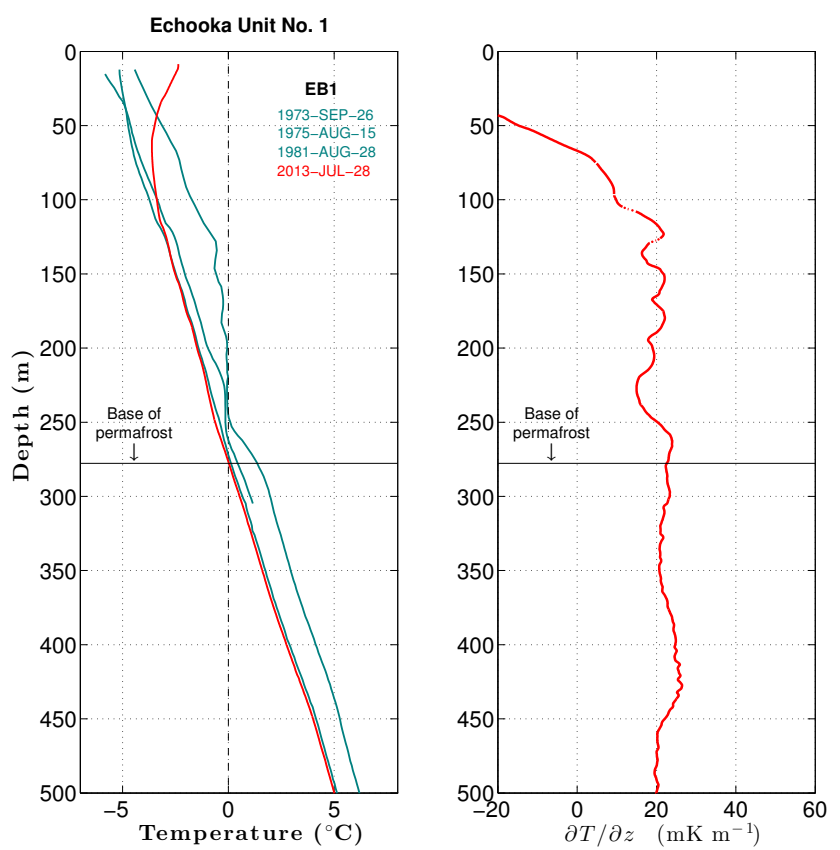

Figure 13. Temperature profiles in the Echooka Unit No. 1 well, color-coded by acquisition date (left). The temperature gradient calculated from the $2013 \log$ is shown in the right panel.
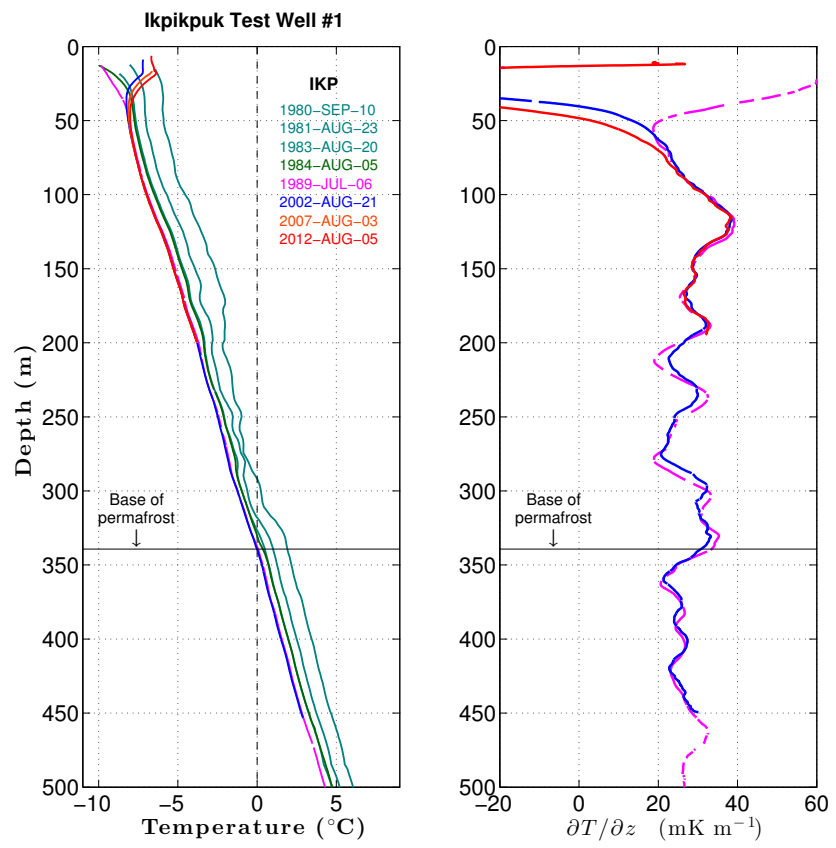

Figure 14. Temperature profiles in the Ikpikpuk Test Well No. 1, color-coded by acquisition date (left). Temperature gradients calculated from the 1989, 2002, and $2012 \operatorname{logs}$ are shown in the right panel.
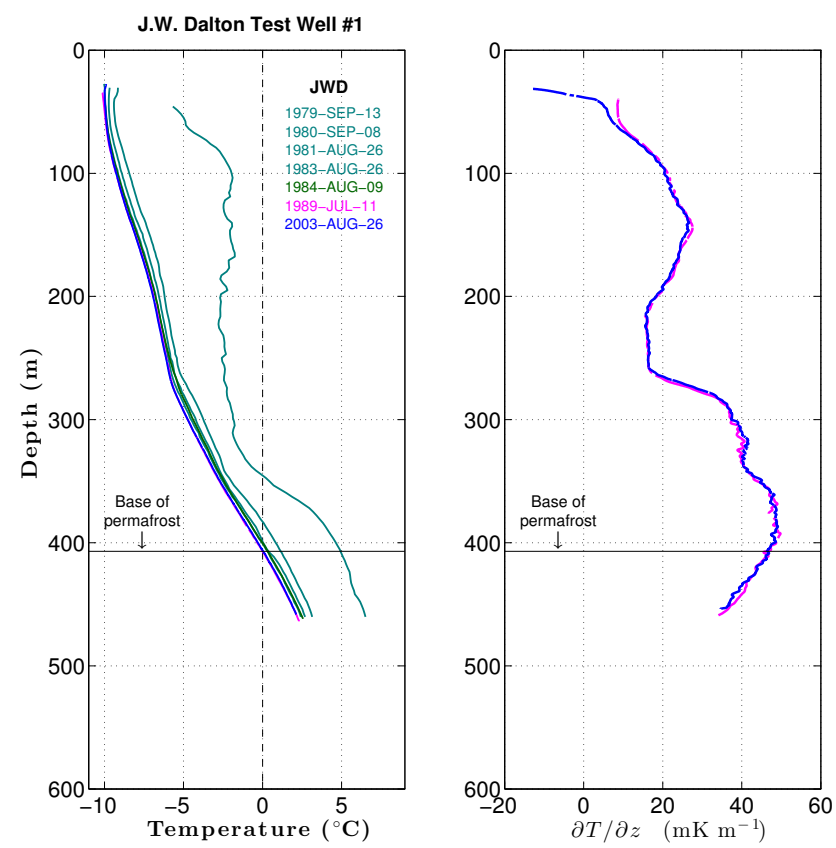

Figure 15. Temperature profiles in the J. W. Dalton Test Well No. 1, color-coded by acquisition date (left). Temperature gradients calculated from the 1989 and 2003 logs are shown in the right panel. 

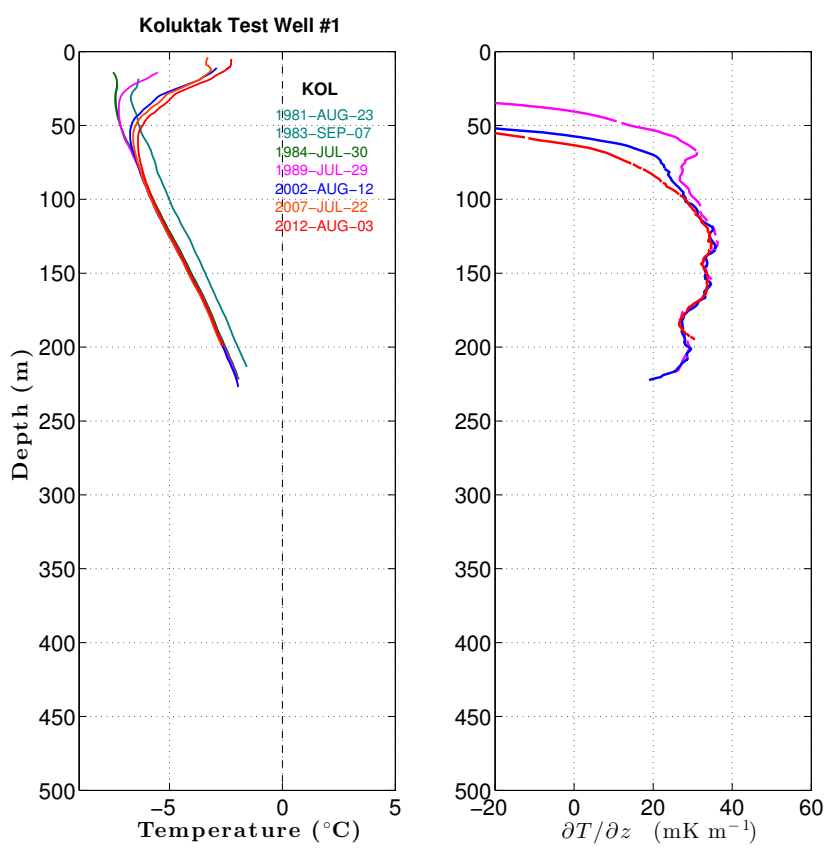

Figure 16. Temperature profiles in the Koluktak Test Well No. 1, color-coded by acquisition date (left). Temperature gradients calculated from the 1989, 2002, and $2012 \operatorname{logs}$ are shown in the right panel. The accessible portion of this well does not reach the base of permafrost.

persisted through at least 1991. The standard uncertainty of the International Temperature Scale of 1990 (ITS-90) temperature measurements made with the current (post-1999) logging system ranges from $3.0 \mathrm{mK}$ at $-60^{\circ} \mathrm{C}$ to $3.3 \mathrm{mK}$ at $0{ }^{\circ} \mathrm{C}$.

\subsection{Data processing}

The processing of the temperature logs consists of several steps that depend on whether the data were acquired at fixed depth intervals (pre-1984) or while the sensor was moving continuously downhole. For the continuously obtained data, the processing steps include (1) correcting the measured resistances for systematic biases, (2) converting the resistances to temperature, (3) removing noise from the signal, and (4) deconvolving the signal to correct for the thermal memory of the probe. The last step is unnecessary for the fixed interval data.

\subsubsection{Resistance corrections}

Several sources of systematic error exist for the temperaturesensor resistance measurements. These include (a) leakage currents between the conductors of the Kelvin circuit due to dirt, moisture, or imperfections in the conductor insulation; (b) capacitance effects; (c) heating of the probe due to the passage of the test current; and (d) thermal EMFs (thermoelectric voltages). These sources are discussed in detail by
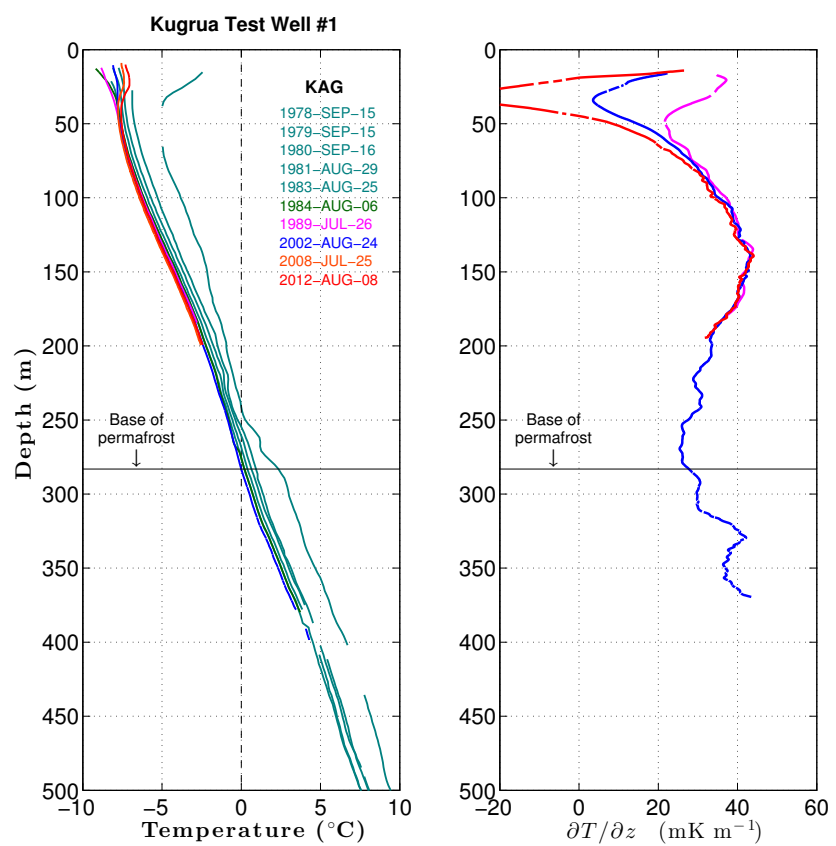

Figure 17. Temperature profiles in the Kugrua Test Well No. 1, color-coded by acquisition date (left). Temperature gradients calculated from the 1989, 2002, and $2012 \operatorname{logs}$ are shown in the right panel.

Clow (2008). The magnitude of the associated resistance offsets can be summarized as follows:

$$
\begin{aligned}
\delta R_{\mathrm{l}} & =\frac{R_{\mathrm{S}}^{2}}{R_{\mathrm{S}}+R_{\mathrm{l}}} \quad \text { (leakage currents), } \\
\delta R_{\mathrm{c}} & =R_{\mathrm{S}} C \frac{\partial R_{\mathrm{S}}}{\partial t} \quad \text { (capacitance effects), } \\
\delta R_{\mathrm{h}} & =\frac{\alpha_{\mathrm{T}}\left(I_{\mathrm{S}} R_{\mathrm{S}}\right)^{2}}{P_{\mathrm{d}}} \quad \text { (self-heating), } \\
\delta R_{\mathrm{e}} & =\frac{V_{\mathrm{emf}}}{I_{\mathrm{S}}} \quad \text { (thermal EMFs), }
\end{aligned}
$$

where $R_{\mathrm{S}}$ is the probe resistance, $R_{1}$ is the interconductor resistance, $C$ is the circuit capacitance, $I_{\mathrm{S}}$ is the test current, $V_{\mathrm{emf}}$ is the sum of the thermoelectric voltages, $\alpha_{\mathrm{T}}$ is the sensors's temperature coefficient of resistance $\left(\alpha_{\mathrm{T}} \equiv R_{\mathrm{S}}^{-1} \partial R_{\mathrm{S}} / \partial T\right), P_{\mathrm{d}}$ is the sensor's power dissipation constant, $T$ is temperature, and $t$ is time. In an attempt to correct for the systematic biases, Eqs. (1)-(4) are applied as corrections to the resistance $\tilde{R}_{\mathrm{S}}$ measured by the logging system's resistance readout to obtain an estimate of the temperature sensor's true resistance,

$R_{\mathrm{S}}=\tilde{R}_{\mathrm{S}}+\left(\delta R_{1}+\delta R_{\mathrm{c}}+\delta R_{\mathrm{h}}-\delta R_{\mathrm{e}}\right)$.

Expressed in terms of temperature, these corrections are generally limited to $0.1-0.2 \mathrm{mK}$. No attempt was made to correct the pre-1991 resistance measurements because the magnitude of the corrections is less than the resolution of the pre1991 resistance readout. 

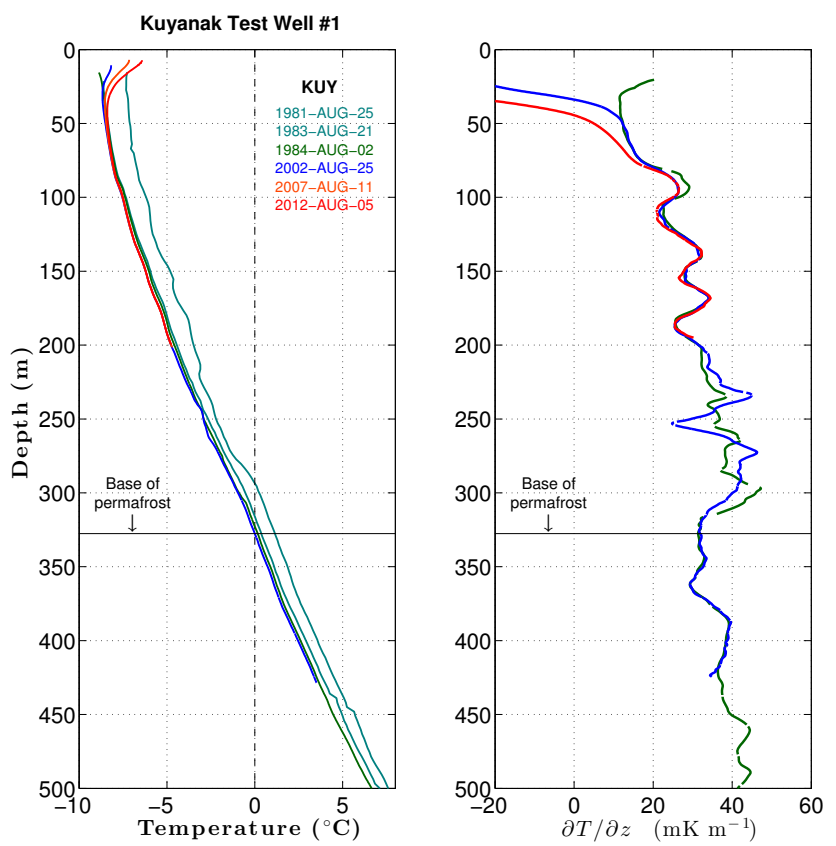

Figure 18. Temperature profiles in the Kuyanak Test Well No. 1, color-coded by acquisition date (left). Temperature gradients calculated from the 1984, 2002, and $2012 \operatorname{logs}$ are shown in the right panel.

\subsubsection{Resistance-to-temperature conversion}

Prior to borehole logging experiments, each sensor is calibrated in a temperature calibration bath at the USGS. A standard platinum resistance thermometer (SPRT) certified by the US National Institute of Standards and Technology is used as the calibration standard. Before 1991, the calibration data for each sensor were fit to the equation proposed by Swartz (1954),

$\mathcal{T}=\frac{a_{0}}{a_{1}+\log R_{\mathrm{s}}}-a_{2}$,

in the manner described by Sass et al. (1971). Using the bestfit values for the calibration constants $\left(a_{0}, a_{1}, a_{2}\right)$, the sensor resistances $R_{\mathrm{S}}$ obtained during a logging experiment are converted to temperature $\mathcal{T}$.

In 1992, a multiyear effort to upgrade certain aspects of the USGS temperature calibration facility was initiated. These upgrades included a higher-quality SPRT, a more sensitive and stable SPRT resistance readout, and a temperature calibration bath with a more stable and uniform temperature field that was also capable of reaching much colder temperatures $\left(-60{ }^{\circ} \mathrm{C}\right)$. In conjunction with these changes, the calibration function used to fit the higher-quality data was changed to

$\mathcal{T}^{-1}=a_{0}+a_{1}\left(\ln R_{\mathrm{S}}\right)+a_{2}\left(\ln R_{\mathrm{S}}\right)^{2}+a_{3}\left(\ln R_{\mathrm{S}}\right)^{3}$,

where $a_{0}, a_{1}, a_{2}$, and $a_{3}$ are now the calibration constants and $\mathcal{T}$ is expressed in Kelvin. This 4-term function offered
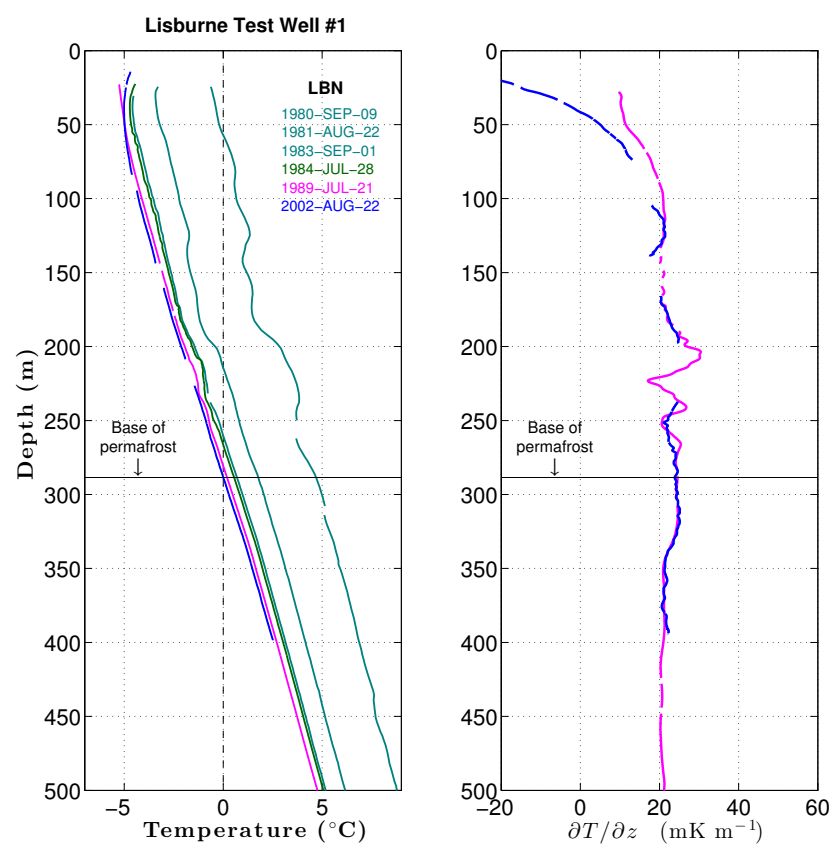

Figure 19. Temperature profiles in the Lisburne Test Well No. 1, color-coded by acquisition date (left). Temperature gradients calculated from the 1989 and 2002 logs are shown in the right panel.

a more precise fit to the calibration data, particularly below $0{ }^{\circ} \mathrm{C}$. Equation (7) is an extension of the often-used 3-term Steinhart-Hart equation (Steinhart and Hart, 1968), which proved inadequate for our purposes. Figure 6 shows sample calibration data and the resulting 4-term calibration fit for one of the USGS temperature sensors.

\subsection{Denoising}

Since the deconvolution step amplifies noise by up to an order of magnitude at periods less than 3-4 probe time constants (45-60s for the DOI/GTN-P borehole records), it is essential to remove as much of the high- and mid-frequency noise as possible before attempting to deconvolve the data. Three different types of noise need to be considered for the DOI/GTN-P temperature records: (1) outliers due to a sudden change in the electric field surrounding the measuring circuit (pre-1999 measurements), (2) instrumental noise, and (3) rapid temperature oscillations due to convection of the borehole fluid. An important consideration is that the frequency content of the climate signal present in these temperature records changes with depth. In addition, the magnitude and frequency of borehole convective noise is sensitive to the temperature gradient $\partial T / \partial z$ and thus also changes with depth. Given the nature of the signal and the noise, simple band-pass filtering cannot be used to remove the noise while still preserving the essence of the climate signal.

For the DOI/GTN-P borehole temperature measurements, denoising is accomplished using a discrete wavelet analysis 

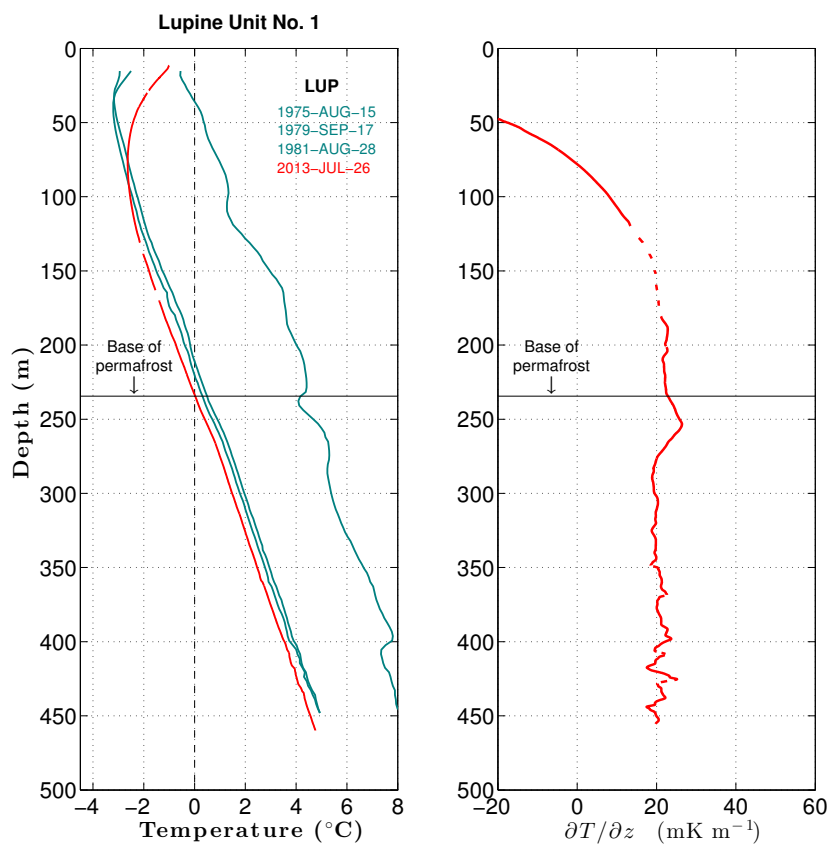

Figure 20. Temperature profiles in the Lupine Unit No. 1 well, color-coded by acquisition date (left). The temperature gradient calculated from the $2013 \mathrm{log}$ is shown in the right panel.
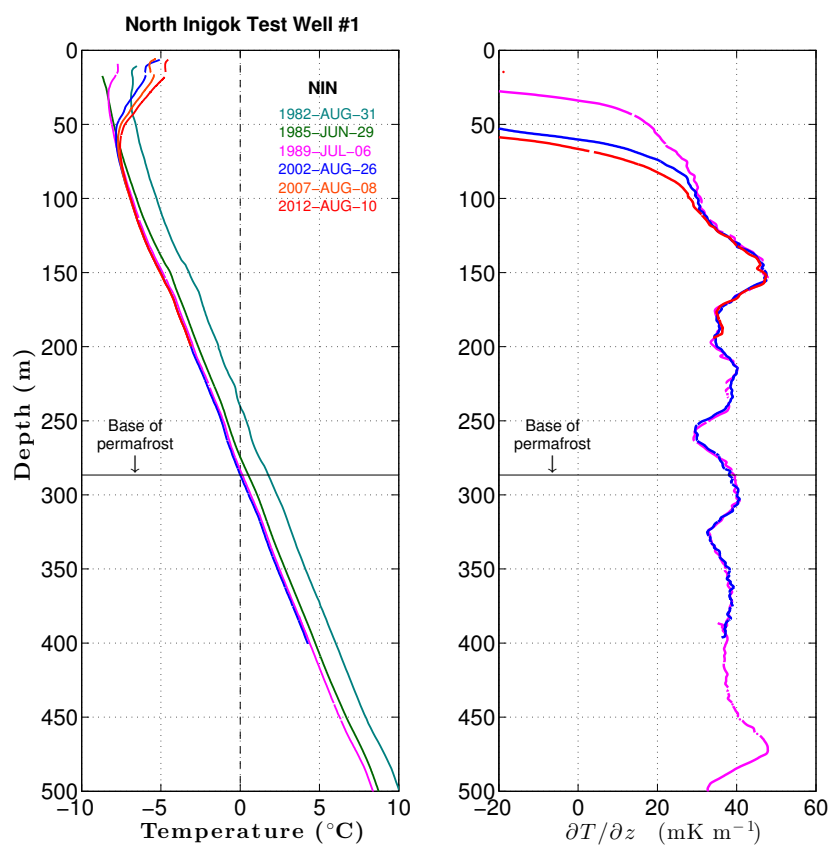

Figure 21. Temperature profiles in the North Inigok Test Well No. 1, color-coded by acquisition date (left). Temperature gradients calculated from the 1989, 2002, and 2012 logs are shown in the right panel.
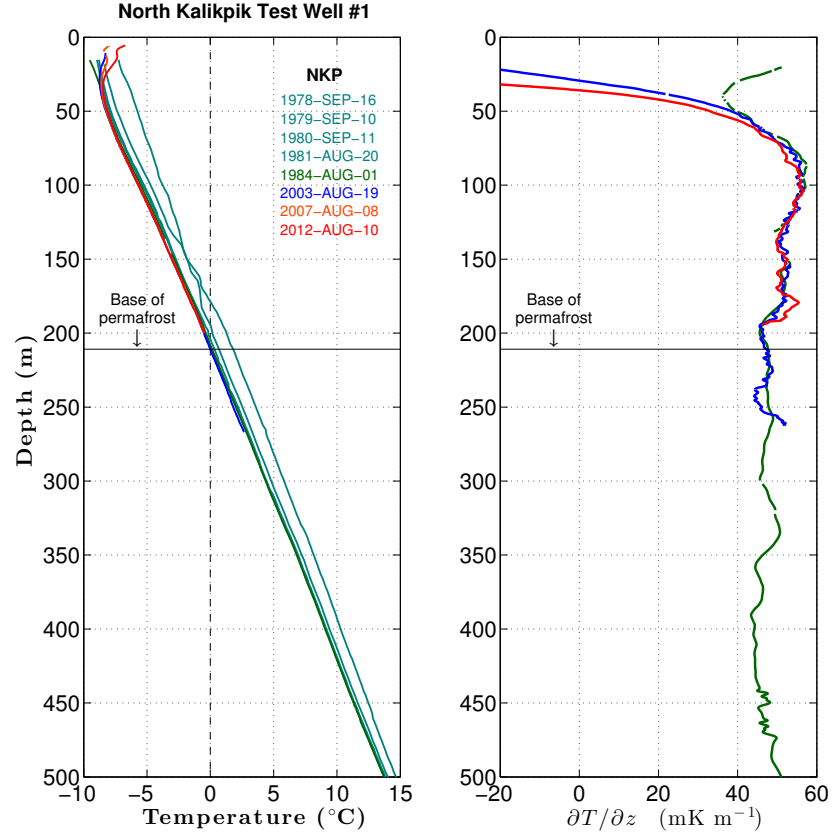

Figure 22. Temperature profiles in the North Kalikpik Test Well No. 1 , color-coded by acquisition date (left). Temperature gradients calculated from the 1984, 2003, and 2012 logs are shown in the right panel.
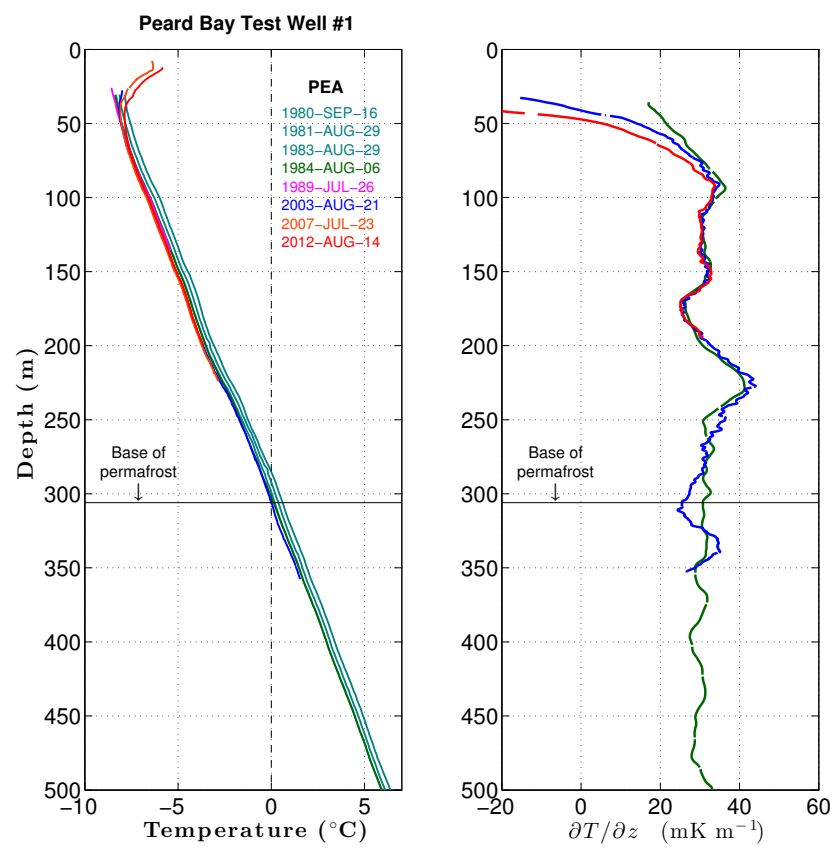

Figure 23. Temperature profiles in the Peard Bay Test Well No. 1, color-coded by acquisition date (left). Temperature gradients calculated from the 1984, 2003, and $2012 \operatorname{logs}$ are shown in the right panel. 

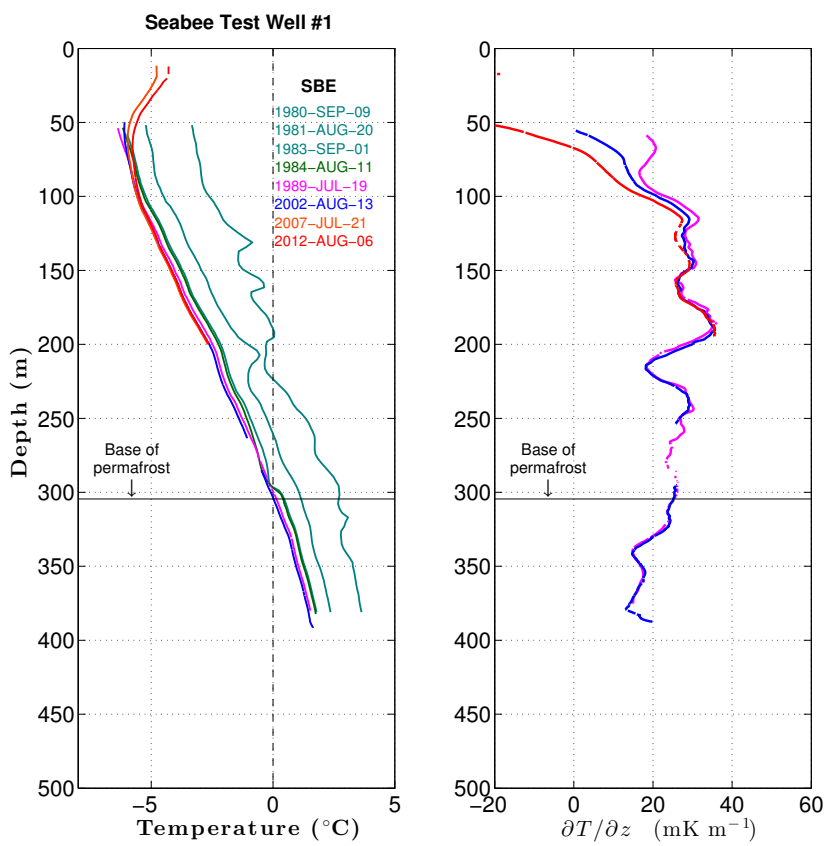

Figure 24. Temperature profiles in the Seabee Test Well No. 1, color-coded by acquisition date (left). Temperature gradients calculated from the 1989, 2002, and $2012 \operatorname{logs}$ are shown in the right panel.
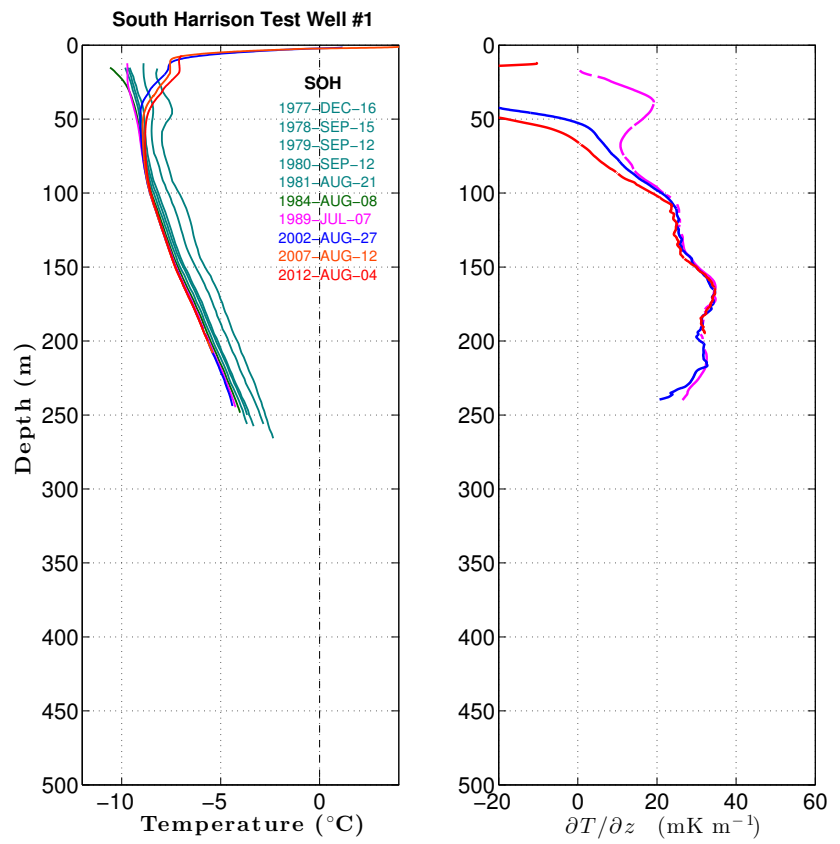

Figure 25. Temperature profiles in the South Harrison Test Well No. 1, color-coded by acquisition date (left). Temperature gradients calculated from the 1989, 2002, and 2012 logs are shown in the right panel. The accessible portion of this well does not reach the base of permafrost.
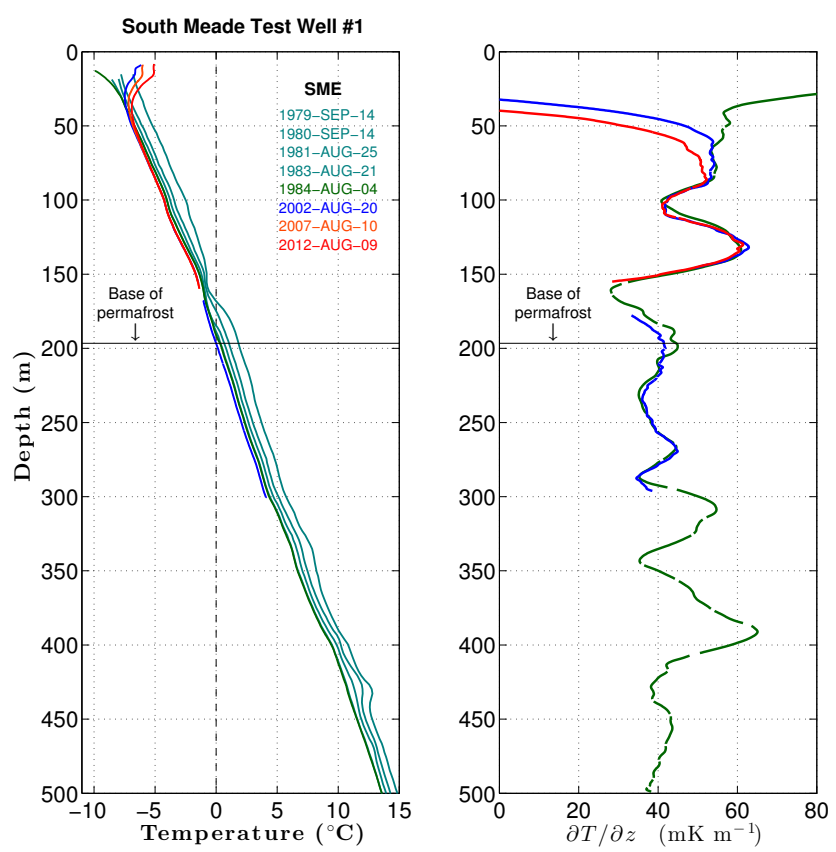

Figure 26. Temperature profiles in the South Meade Test Well No. 1, color-coded by acquisition date (left). Temperature gradients calculated from the 1984, 2002, and 2012 logs are shown in the right panel.

(Strang and Nguyen, 1996). Wavelet denoising allows thresholds to be set so that a real signal rising above the noise can be preserved while noise is removed, even if they occur at the same frequency. Given the smooth nature of the underlying temperature signal, order-3 coiflets were selected for the analyzing wavelets; these wavelets appear ideal for this purpose, being relatively smooth and nearly symmetric. Wavelet denoising was performed at spatial scales finer than $3.4 \mathrm{~m}$ (periods $\leq 64 \mathrm{~s}$ ) for the post-1991 logs, and finer than $5.0 \mathrm{~m}$ for the earlier continuous logs. The top and bottom of the logs were extended slightly to minimize border distortion. During the first pass through the wavelet denoising, data points more than 3.5 standard deviations from the smooth denoised signal are identified as outliers and removed. As the outliers may have distorted the denoised signal on the first pass, the outlier-free data are passed through the wavelet denoising a second time. Figure 7 shows the temperature measurements and resulting denoised signal from a portion of a representative DOI/GTN-P temperature log.

Incrementally obtained temperature logs (pre-1984) were not denoised as they contain insufficient information to perform the kind of denoising analysis described above. In addition, noise amplification during the deconvolution step is not a concern since these logs do not require a temporal deconvolution. 

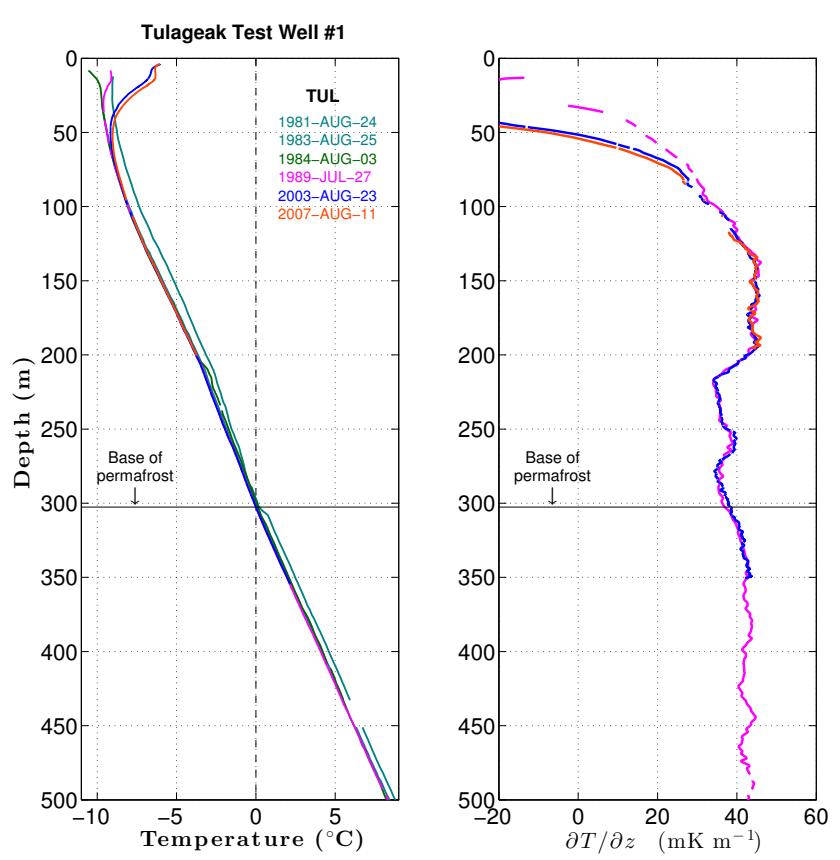

Figure 27. Temperature profiles in the Tulageak Test Well No. 1, color-coded by acquisition date (left). Temperature gradients calculated from the 1989, 2003, and $2007 \operatorname{logs}$ are shown in the right panel.
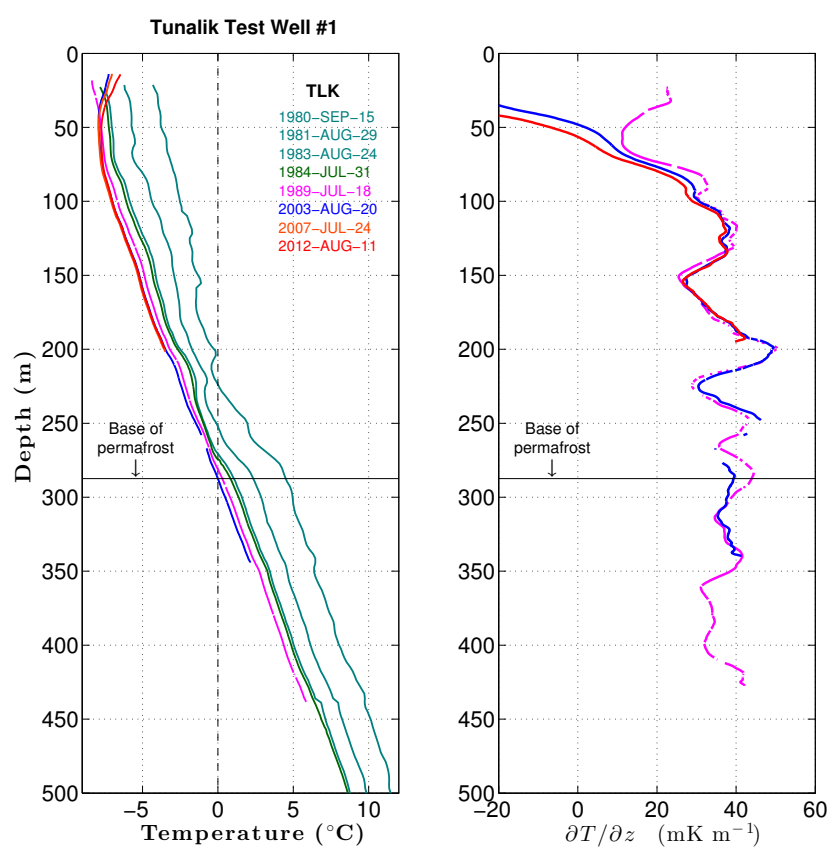

Figure 28. Temperature profiles in the Tunalik Test Well No. 1, color-coded by acquisition date (left). Temperature gradients calculated from the 1989, 2003, and $2012 \operatorname{logs}$ are shown in the right panel.

\subsubsection{Deconvolution}

The USGS temperature probes have a time constant $\tau$ of 7$15 \mathrm{~s}$, depending on the thermophysical properties of the fluid filling the borehole. Since $\tau$ is greater than the sampling rate $(2 \mathrm{~s})$, a measurement represents an average of what the probe has experienced during the last few time constants. More exactly, the temperature measurements $\mathcal{T}$ are given by the convolution of the actual temperatures in the borehole $(T)$ with the logging system's impulse response function $h(t)$,

$\mathcal{T}(t)=\int_{-\infty}^{\infty} h(t-\mu) T(\mu) d \mu$.

Given the low capacitance of the system's measurement circuit, the system response is dominated by the characteristics of the temperature probe. Following Nielsen and Balling (1984), the impulse response function is taken to be

$h(t)= \begin{cases}0, & t<t_{\mathrm{o}} \\ \frac{1}{\tau} \exp \left(-\frac{t-t_{\mathrm{o}}}{\tau}\right), & t \geq t_{\mathrm{o}},\end{cases}$

where $t_{\mathrm{o}}$ is the time delay before the system begins to sense a temperature change. Time constant experiments with the USGS temperature sensors indicate $t_{\mathrm{O}}$ is much less than the sampling rate (Saltus and Clow, 1994).

Recognizing that a temperature log is a finite-length discrete sampling of the actual temperatures in a borehole, Eq. (8) can be approximated by the summation,

$\mathcal{T}_{i}=\sum_{j=1}^{n} h_{j} T_{i-j+1}$

where $n$ is the number of terms in the response function $h$. Using serial division, Eq. (10) can be inverted to find the actual borehole temperatures in terms of the measurements (Saltus and Clow, 1994),

$T_{i}=\frac{\mathcal{T}_{i}-\sum_{j=1}^{n-1} h_{j+1} T_{i-j}}{h_{1}}, \quad i \geq 2$.

Beginning in 1991, the temperature sensor was always allowed to reach thermal equilibrium at a fixed depth in the borehole fluid before beginning to move the sensor downhole. In this case, the first value $T_{1}$ is equal to the measured value $\mathcal{T}_{1}$, and we can take $T_{i-j}=\mathcal{T}_{1}$ when $(i-j) \leq 0$ in Eq. (11). This procedure was generally not used for the pre-1991 temperature logs. Rather, the temperature sensor was lowered from the surface into the borehole fluid without pausing. The deconvolution errors for the first $60 \mathrm{~s}(3-4 \tau)$ of these logs are quite large. Hence, the upper few meters of the 1984-1991 logs are discarded. Returning to Fig. 7, we can see the relationship between the actual temperatures in 
a borehole (deconvolved signal) and the measurements obtained by the logging system for a sample DOI/GTN-P temperature $\log$.

\section{DOI/GTN-P borehole temperatures}

\subsection{Temperature-depth profiles}

The processed temperature-depth profiles $T(z)$ derived from the 1973-2013 DOI/GTN-P borehole logs are shown in Figs. 8-30. Digital versions of the temperature profiles are available from the Advanced Cooperative Arctic Data and Information Service (ACADIS) repository (Clow, 2013). Gaps apparent in some of the profiles are almost entirely due to logging tool hang-ups. These occur when the temperature sensor temporarily "hangs" on a borehole casing weld or other minor obstruction and then subsequently slips by. Due to the sensor's relatively long time constant and uncertainties regarding the sensor's actual location during these hangups, it is difficult to recover the true well temperatures at these locations. The data are masked in these sections to avoid reporting erroneous values. Since the focus of current well-monitoring efforts is to capture climate-change effects, the more recent temperature logs are generally made only to $\sim 200 \mathrm{~m}$ as little temperature change is expected beyond this depth. Efforts to occasionally log beyond $200 \mathrm{~m}$ will still be made in the future in an attempt to track small changes in the base of permafrost over time.

\subsection{Drilling disturbance}

The DOI/GTN-P monitoring wells were drilled using conventional rotary drilling techniques. In the process, a drilling fluid is pumped downhole through the drill pipe to the bottom of the well to pick up the drill cuttings for return to the surface via the annulus between the drill pipe and the borehole wall. As a result, heat is exchanged between the circulating drill fluid and the borehole wall at a rate that depends on their relative temperature difference and the physical properties of the two media. As the fluid tends to take on the average temperature of the rock column penetrated by the borehole, the net effect is to cool the lower portion of a deep borehole while the upper portion warms. After cessation of drilling, temperatures in the well and surrounding rock gradually return to the undisturbed predrilling condition. As these wells were drilled to much greater depths (up to $6 \mathrm{~km}$ ) than the portion that has remained accessible for temperature logging, all the logs were acquired from the upper zone that was warmed by drilling. As a result, the DOI/GTN-P temperature profiles exhibit a gradual cooling over time (left panels, Figs. 8-30).

Although the transfer of heat within a well during drilling is a complicated process, the recovery of a well from the drilling disturbance can be approximated by a simple relationship for times not too soon after well completion. If $t$ is the time since the drill bit first reached a given depth $z$ and $s$ is the duration of the drilling disturbance at that depth (i.e., the duration of fluid circulation), then the temperature at depth $z$ and time $t$ can be approximated by

$T(z, t)=T_{0}(z)+\frac{\bar{q}_{1}}{4 \pi K}\left[\ln \left(\frac{t}{t-s}\right)-\frac{a^{2}}{2 \kappa s}\left(\frac{s}{t}\right)^{2}+O\left(\frac{s}{t}\right)^{3}\right]$,

where $T_{0}(z)$ is the undisturbed predrilling temperature, $K$ is the thermal conductivity of the surrounding rock, $\kappa$ is the rock's thermal diffusivity, $a$ is the borehole radius, and $\bar{q}_{1}$ is the mean heat flux from the drilling fluid into the surrounding rock per unit length of borehole (Lachenbruch and Brewer, 1959). The validity of this expression is restricted to times $t \gg s$. If we let $\tau \equiv(t / s)$ represent dimensionless time, Eq. (12) can be re-expressed as

$T(z, \tau)=T_{\mathrm{o}}(z)+\frac{\bar{q}_{1}}{4 \pi K}\left[\ln \left(1+\frac{1}{\tau}\right)-\frac{1}{2 F_{\mathrm{s}} \tau^{2}}+O\left(\tau^{-3}\right)\right]$,

where $F_{\mathrm{S}} \equiv\left(\kappa s / a^{2}\right)$ is the dimensionless source-function Fourier number. For the DOI/GTN-P temperature logs, $\tau$ is large enough that the term on the order of $\tau^{-3}$ is negligible and can be ignored. The second term in brackets takes into account the finite dimension of a well and is only important when the product $F_{\mathrm{s}} \tau^{2}$ is small. Most of the DOI/GTN-P monitoring wells were drilled over a few months and have associated Fourier numbers $F_{\mathrm{S}}$ in the range 100-300, while the remaining wells took roughly a year to drill and have $F_{\mathrm{S}}$ values exceeding 1500. Given these large Fourier numbers, the second term in brackets (Eq. 13) is small and can be safely ignored under the conditions for which the equation is valid $(t \gg s)$.

Figure 31 shows the recovery of temperatures from the drilling disturbance in one of the DOI/GTN-P monitoring wells (Atigaru Test Well No. 1). The temperatures do indeed recover in the manner predicted by Eq. (13) for $\tau>8$. The right panel of Fig. 31 shows the evolution of the thermal drilling disturbance,

$\Delta T_{\mathrm{d}}(z, \tau)=T(z, \tau)-T_{\mathrm{o}}(z)$,

over time. For the last log obtained in the Atigaru well (13 August 2007), the drilling disturbance had dissipated to the extent that temperatures were within $0.03-0.05 \mathrm{~K}$ of the undisturbed predrilling condition. Table 2 lists the drilling disturbance values $\left(\Delta T_{\mathrm{d}}\right)$ for all the DOI/GTN-P wells during the 1989, 2002-2003, 2007-2008, and 2012-2013 field campaigns. With the exception of the Tunalik Test Well, the drilling disturbances remaining in the DOI/GTN-P monitoring wells were on the order of $0.1 \mathrm{~K}$ or less by the early 2000s. For all but five of the wells (AWU, LBN, NIN, SBE, TLK), $\Delta T_{\mathrm{d}}$ was on the order of $0.1 \mathrm{~K}$ or less substantially earlier (i.e., by 1989). 
Table 2. Drilling disturbance $\Delta T_{\mathrm{d}}$ remaining in the DOI/GTN-P monitoring wells at the time of the 1989, 2002-2003, 2007-2008, and 2012-2013 field campaigns. The corresponding dimensionless times $\tau$ are also listed.

\begin{tabular}{|c|c|c|c|c|c|c|c|c|c|c|}
\hline \multirow[t]{2}{*}{ Borehole } & \multirow{2}{*}{$\begin{array}{l}\text { USGS } \\
\text { Code }\end{array}$} & \multirow{2}{*}{$\begin{array}{r}\text { Drilling } \\
\text { Duration } \\
\text { (days) }\end{array}$} & \multicolumn{2}{|r|}{1989} & \multicolumn{2}{|c|}{ 2002-2003 } & \multicolumn{2}{|c|}{ 2007-2008 } & \multicolumn{2}{|c|}{ 2012-2013 } \\
\hline & & & $\tau$ & $\Delta T_{\mathrm{d}}(\mathrm{K})$ & $\tau$ & $\Delta T_{\mathrm{d}}(\mathrm{K})$ & $\tau$ & $\Delta T_{\mathrm{d}}(\mathrm{K})$ & $\tau$ & $\Delta T_{\mathrm{d}}(\mathrm{K})$ \\
\hline Atigaru Test Well No. 1 & ATI & 60 & 76 & $0.07-0.13$ & 156 & $0.03-0.06$ & 186 & $0.03-0.05$ & - & - \\
\hline Awuna Test Well No. 1 & AWU & 412 & 8 & $0.20-0.33$ & 20 & $0.09-0.14$ & 25 & $0.07-0.11$ & 29 & $0.06-0.10$ \\
\hline Drew Point Test Well No. 1 & DRP & 54 & 78 & $0.05-0.09$ & 173 & $0.02-0.04$ & 200 & $0.02-0.04$ & - & - \\
\hline East Simpson Test Well No. 1 & ESN & 44 & 87 & $0.07-0.11$ & 195 & $0.03-0.05$ & 236 & $0.03-0.04$ & 278 & $0.03-0.04$ \\
\hline East Teshekpuk Test Well No. 1 & ETK & 56 & 87 & $0.05-0.09$ & 179 & $0.02-0.04$ & 205 & $0.02-0.04$ & - & - \\
\hline Echooka Unit No. 1 & EB1 & 160 & - & - & - & - & - & - & 94 & $0.04-0.05$ \\
\hline Ikpikpuk Test Well No. 1 & IKP & 442 & 9 & $0.09-0.16$ & 20 & $0.04-0.07$ & 24 & $0.04-0.06$ & 28 & $0.03-0.05$ \\
\hline J. W. Dalton Test Well No. 1 & JWD & 86 & 43 & $0.10-0.16$ & 103 & $0.04-0.07$ & - & - & - & - \\
\hline Koluktak Test Well No. 1 & KOL & 24 & 127 & 0.04 & 326 & $0.01-0.02$ & 401 & 0.01 & 477 & 0.01 \\
\hline Kugrua Test Well No. 1 & KAG & 98 & 43 & $0.13-0.16$ & 91 & $0.06-0.07$ & 113 & $0.05-0.06$ & 129 & $0.04-0.05$ \\
\hline Kuyanak Test Well No. 1 & KUY & 42 & - & - & 186 & $0.03-0.05$ & 229 & $0.03-0.04$ & 273 & $0.02-0.03$ \\
\hline Lisburne Test Well No. 1 & LBN & 344 & 11 & $0.35-0.40$ & 25 & $0.12-0.18$ & - & - & - & - \\
\hline Lupine Unit No. 1 & LUP & 309 & - & - & - & - & - & - & 46 & $0.07-0.09$ \\
\hline North Inigok Test Well No. 1 & NIN & 45 & 68 & $0.33-0.38$ & 175 & $0.13-0.15$ & 215 & $0.10-0.12$ & 256 & $0.09-0.10$ \\
\hline North Kalikpik Test Well No. 1 & NKP & 40 & - & - & 233 & $0.04-0.05$ & 269 & $0.03-0.04$ & 315 & 0.03 \\
\hline Peard Bay Test Well No. 1 & PEA & 73 & 53 & $0.10-0.11$ & 123 & $0.04-0.05$ & 143 & 0.04 & 168 & 0.03 \\
\hline Seabee Test Well No. 1 & SBE & 257 & 14 & $0.19-0.26$ & 33 & $0.08-0.11$ & 40 & $0.07-0.09$ & 47 & $0.06-0.08$ \\
\hline South Harrison Test Well No. 1 & $\mathrm{SOH}$ & 67 & 69 & $0.14-0.15$ & 140 & $0.07-0.08$ & 167 & 0.06 & 195 & 0.05 \\
\hline South Meade Test Well No. 1 & SME & 341 & - & - & 26 & $0.06-0.11$ & 32 & $0.05-0.09$ & 37 & $0.04-0.08$ \\
\hline Tulageak Test Well No. 1 & TUL & 22 & 140 & $0.03-0.05$ & 373 & $0.01-0.02$ & 439 & 0.01 & - & - \\
\hline Tunalik Test Well No. 1 & TLK & 407 & 10 & $0.53-0.67$ & 22 & $0.24-0.29$ & 26 & $0.20-0.26$ & 30 & $0.17-0.22$ \\
\hline West Dease Test Well No. 1 & WDS & 36 & 96 & $0.05-0.08$ & - & - & - & - & - & - \\
\hline West Fish Creek Test Well No. 1 & FCK & 67 & 68 & $0.15-0.16$ & - & - & 171 & 0.06 & 193 & $0.05-0.06$ \\
\hline
\end{tabular}
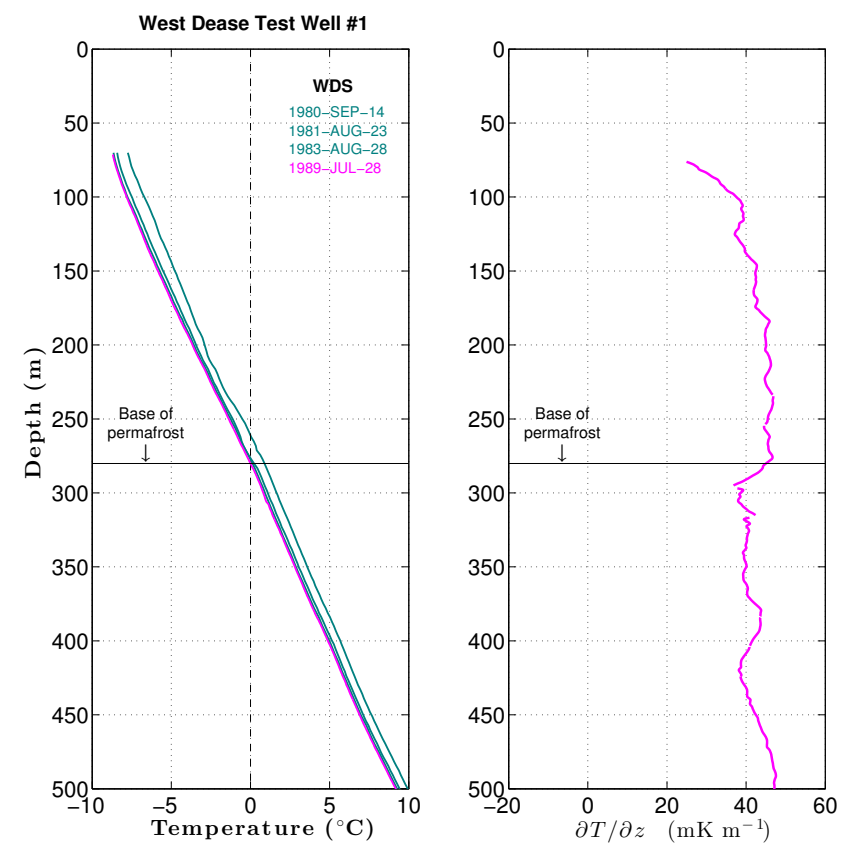

Figure 29. Temperature profiles in the West Dease Test Well No. 1, color-coded by acquisition date (left). Temperature gradient calculated from the $1989 \log$ is shown in the right panel.
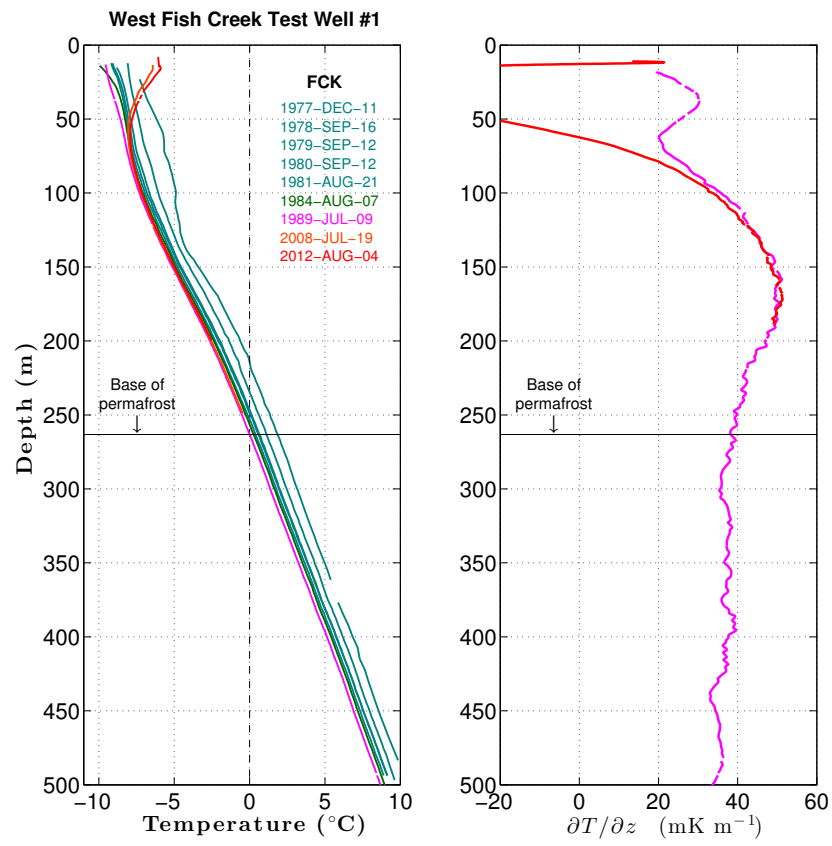

Figure 30. Temperature profiles in the West Fish Creek Test Well No. 1 , color-coded by acquisition date (left). Temperature gradients calculated from the 1989 and $2012 \operatorname{logs}$ are shown in the right panel. 

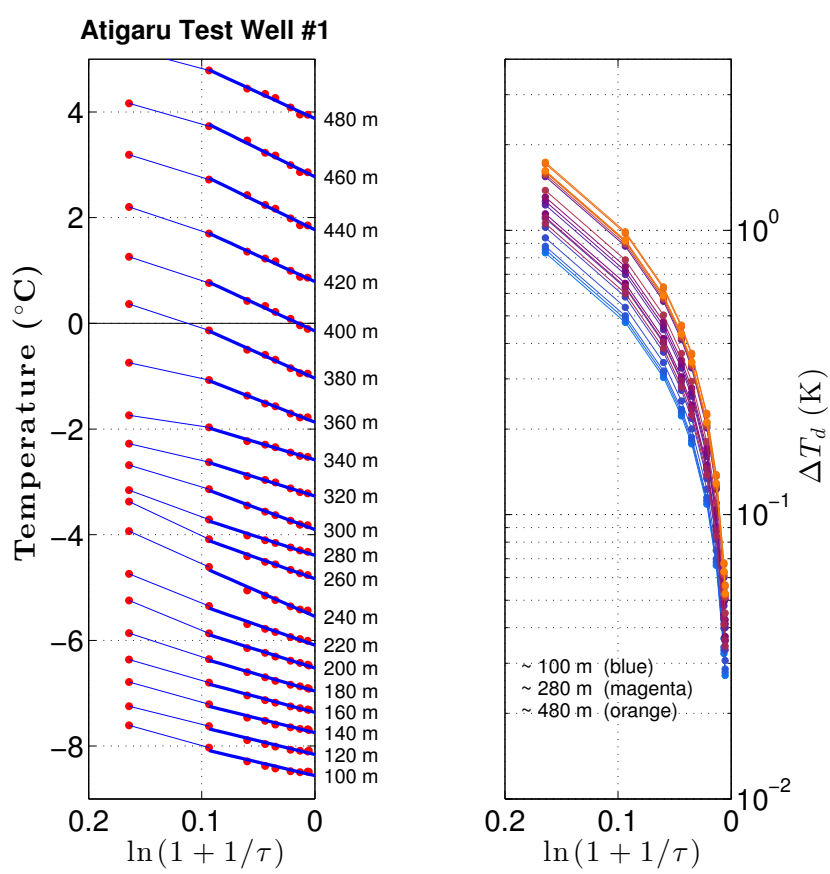

Figure 31. Recovery of temperatures from the thermal drilling disturbance at fixed depths in the Atigaru Test Well No. 1 (left). In this case, the earliest log was obtained at dimensionless time $\tau=5.6$, or $\ln (1+1 / \tau)=0.16$. Complete thermal recovery occurs as $\ln (1+1 / \tau)$ approaches zero $(\tau \rightarrow \infty)$. A least-squares fit to the temperature data for times $\tau>8$ provides values for the undisturbed temperature profile $T_{\mathrm{O}}(z)$ and the factor $\bar{q}_{1} /(4 \pi K)$ (dark blue lines). With these values, the evolution of the thermal drilling disturbance $\Delta T_{\mathrm{d}}$ (right panel) can be found using Eqs. (13) and (14).

\subsection{Latent heat effects}

Many of the wells display an abnormally slow recovery for intervals within the permafrost layer, particularly at small dimensionless times $\tau$. The Echooka, J. W. Dalton, and Seabee test wells are good examples (Figs. 13, 15, 24), as is the $250 \mathrm{~m}$ depth in the Atigaru well (Fig. 8). This slow recovery is attributable to latent heat effects. While drilling a deep borehole through permafrost, interstitial ice within the permafrost zone generally thaws in the vicinity of the well. Once the well is completed, the thawed interstitial ice releases its latent heat upon refreezing, retarding the cooling process as the permafrost returns to its predrilling state. Permafrost intervals showing a delayed recovery are likely to have appreciable amounts of interstitial ice. An extensive discussion of latent heat effects in the cold permafrost found on the Arctic Slope can be found in Lachenbruch et al. (1982). In warm permafrost (mean annual surface temperature $>-2^{\circ} \mathrm{C}$ ), latent heat effects in the surficial layer at the top of permafrost can strongly modulate the response of the underlying ground to climate change (Riseborough, 1990; Romanovsky et al., 2010). These effects are much less important on the cold Arctic Slope.

\subsection{Temperature gradients}

Temperature gradients $\partial T / \partial z$ calculated from select temperature profiles are shown in the right panels of Figs. 8-30 for all of the DOI/GTN-P monitoring wells. Except for the upper $100 \mathrm{~m}$ where climate-change effects are large, the gradients primarily reflect thermal conductivity variations with depth; thermal profiles undisturbed by latent heat effects were used wherever possible to find the gradients. A $10 \mathrm{~m}$ averaging interval was used for the gradient calculations, 2-3 times greater than the spatial scales at which the wavelet denoising and deconvolution operate. In most cases, the thermal gradient determined in this way shows good agreement among logs for any given well. Depths below $100 \mathrm{~m}$ where the gradient $\partial T / \partial z$ between logs is disparate indicate intervals where one or more of the temperature profiles is less certain. Unlike nearby Prudhoe Bay, a significant change in the temperature gradient is not observed at the base of permafrost in the NPR-A wells or in the Lupine or Echooka test wells; the strong gradient contrast at the base of permafrost in Prudhoe Bay has been attributed to the high porosity $(\sim 39 \%)$ of the saturated coarse-grained materials found there (Lachenbruch et al., 1982).

\subsection{Borehole fluid convection}

The fluid in a monitoring well is expected to freely convect wherever the temperature gradient exceeds a value given by the sum of a lapse rate term and the critical potentialtemperature gradient,

$$
\frac{\partial T}{\partial z}>\frac{g \alpha T}{c_{\mathrm{p}}}+\left(\frac{\partial \theta}{\partial z}\right)_{\text {crit }} .
$$

Here, $\alpha$ is the coefficient of thermal expansion for the borehole fluid, $c_{\mathrm{p}}$ is its specific heat, $g$ is the gravitational acceleration, and $T$ is temperature expressed in Kelvin. The critical potential-temperature gradient,

$\left(\frac{\partial \theta}{\partial z}\right)_{\text {crit }}=\frac{\nu \kappa}{\alpha g a^{4}}\left(R a_{\mathrm{c}} \gamma^{4}\right)$,

accounts for the effects of viscous drag within the fluid and the boundary conditions at the wall of the borehole; $v$ is the kinematic viscosity of the fluid, $\kappa$ is its thermal diffusivity, $a$ is the borehole radius, $\gamma \equiv(a / L)$ is the aspect ratio for convective cells of height $L$, and $R a_{\mathrm{c}}$ is the critical Rayleigh number. Charlson and Sani $(1970,1971)$ found that the minimum $\left(R a_{\mathrm{c}} \gamma^{4}\right)$ value at which convection will occur is 71 for perfectly insulating side walls and 220 for perfectly conducting walls. Using the thermal properties of the DOI/GTN-P borehole fluid (diesel oil) and the radius of the boreholes (12$17 \mathrm{~cm}$ ), and assuming thermally conducting sidewalls (a reasonable assumption for these wells), the lapse rate term is $1.44 \mathrm{mK} \mathrm{m}^{-1}$, while the critical potential-temperature gradient is much smaller, $0.007-0.028 \mathrm{mK} \mathrm{m}^{-1}$. Thus, the viscosity of the fluid and resistive drag on the walls is small enough 


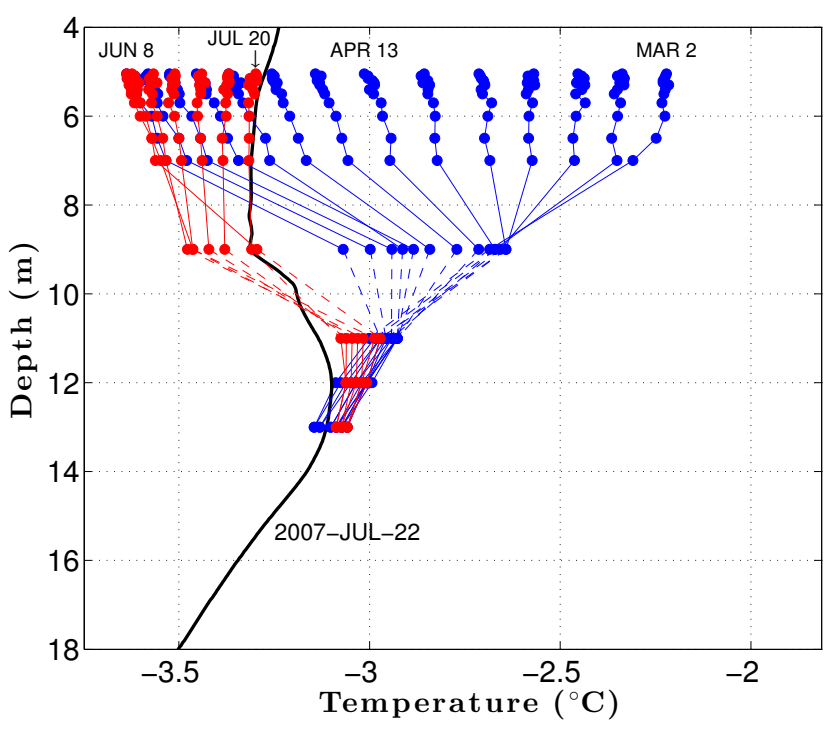

Figure 32. Temperatures in the Koluktak Test Well No. 1 measured by a thermistor string extending over the $5-13 \mathrm{~m}$ depths from 2 March through 20 July (2007); thermistor string temperatures are displayed once per week. The thermistor string was removed from the well and a standard borehole temperature log acquired on 22 July 2007 (black line). The thermistor string data confirm the development of a nearly isothermal zone in the upper $10 \mathrm{~m}$ of the well due to intense convection during the spring and early summer.

that the onset of convection in these wells is predominantly determined by the lapse rate term. Considering both terms, free convection is expected to occur at all depths where the temperature gradient exceeds $1.47 \mathrm{mK} \mathrm{m}^{-1}$. Except for the climate-induced gradient reversal near the surface, the temperature gradients in these wells exceed the value necessary for the onset of convection by more than an order of magnitude. Thus the form of the convective flow is expected to be fully turbulent. Analysis of the temperature logs confirms that the borehole fluid is undergoing turbulent convection. Random temperature fluctuations as large as $\pm 10 \mathrm{mK}$ associated with the turbulent eddies constitute the primary source of noise in the post-1999 temperature logs.

During the spring and early summer, temperature gradients typically exceed $100 \mathrm{mK} \mathrm{m}^{-1}$ in the upper $\sim 10 \mathrm{~m}$ of permafrost. As a result, convection of the borehole fluid can become so intense that the temperatures within the monitoring wells become nearly isothermal during this period at shallow depths. Figure 32 shows temperatures in the Koluktak Test Well monitored by a thermistor string located 5$13 \mathrm{~m}$ below the surface. Strong positive temperature gradients develop near the surface by early March as the permafrost chills. By early June, the isothermal zone extends down to $10 \mathrm{~m}$ in this well and then warms in response to summer heating. By early to mid-August, near-surface gradients weaken, shallow convection ceases, and the isothermal zone vanishes. As most of the DOI/GTN-P temperature logs have

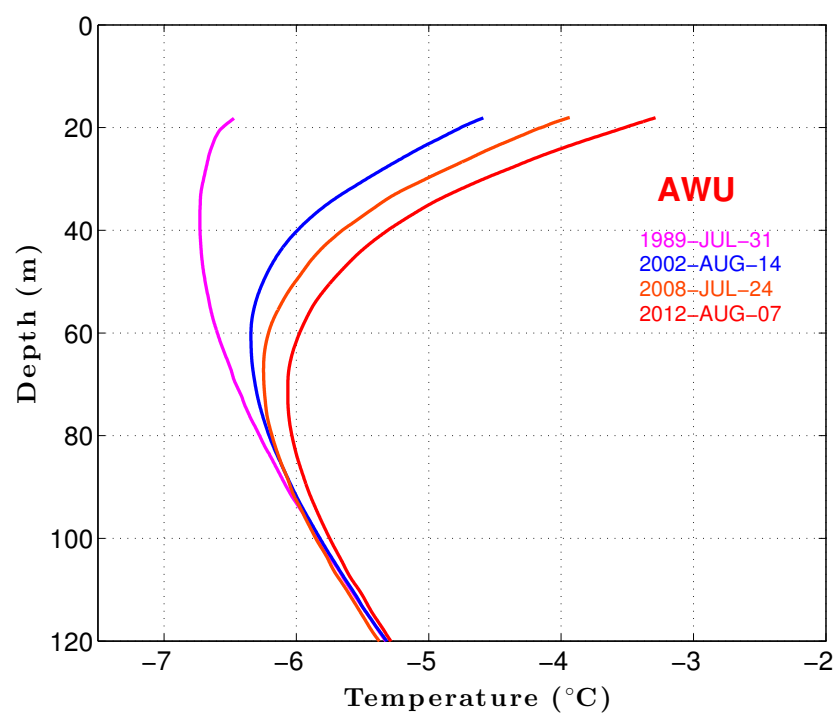

Figure 33. Upper portion of the last four temperature logs from the Awuna Test Well No. 1. Near-surface permafrost temperatures have warmed substantially at this site since the late 1980s in response to climate change. Seasonal effects in the upper $18 \mathrm{~m}$ have been removed to more clearly show the climate signal.

been acquired at about the convective transition period, many of the logs show an isothermal section in the upper $\sim 10 \mathrm{~m}$ while others do not.

\subsection{Climate-change effects}

Although the temperatures in this data set have not been corrected for the thermal drilling disturbance, measurements acquired during the last $25 \mathrm{yr}$ when the disturbance has been small demonstrate the magnitude of permafrost warming experienced on the Arctic Slope of Alaska since the late 1980s. Figure 33 shows the last four temperature logs acquired in the Awuna Test Well as an example. Correcting the logs for the drilling disturbance is a high priority as it will give a clearer picture of how near-surface temperatures in permafrost have evolved in this region since the onset of the monitoring program in 1973. A preliminary analysis of the well log data indicates a spatially variable warming has occurred across with the Arctic Slope of Alaska, with temperature increases ranging $2-3 \mathrm{~K}$ at the $20 \mathrm{~m}$ depth since the late $1980 \mathrm{~s}$.

\section{Summary}

A $40 \mathrm{yr}$ data set of borehole temperature measurements from continuous permafrost in Arctic Alaska has been assembled for the period 1973-2013. The data represent the true temperatures in the wellbores and surrounding rocks at the time of the measurements; they have not been corrected to remove the thermal disturbance caused by drilling the wells. With a few exceptions, the drilling disturbance is estimated to have 
been on the order of $0.1 \mathrm{~K}$ or less by 1989 . Thus, most of the temperature measurements acquired during the last $25 \mathrm{yr}$ are little affected by the drilling disturbance. The data contribute to ongoing efforts to monitor changes in the thermal state of permafrost in both hemispheres by the Global Terrestrial Network for Permafrost (GTN-P), one of the primary subnetworks of the Global Terrestrial Observing System (GTOS). In addition, the data will be useful for refining our basic understanding of the physical conditions in near-surface materials on the Arctic Slope of Alaska, including the thickness of permafrost and its ice content, as well as provide important information for validating predictive models used for climate impact assessments. The data set may also prove useful for testing the validity of borehole recovery models used to describe how the thermal disturbance caused by drilling diminishes over time. Such models are often used to ascertain undisturbed rock temperatures from a series of temperature logs perturbed by drilling effects. Very few high-quality data sets are available for testing such models, particularly in permafrost terrain. The fully processed borehole temperature data are available online from the ACADIS repository at doi:10.5065/D6N014HK.

Acknowledgements. We gratefully acknowledge funding support from a number of USGS programs that have made acquisition of this data set possible over the years, including the Earthquakes, Volcanoes, and Engineering Program; the Earth System Dynamics Program; and most recently the Climate and Land Use Change Program. Logistics support from BLM's Arctic District Office has been greatly appreciated. Special thanks go to J. Kennelly and M. Ohms, whose expertise has kept the instrumentation running, and especially to Art Lachenbruch for his insight regarding the potential for extracting climate information from permafrost temperature profiles. Any use of trade, firm, or product names is for descriptive purposes only and does not imply endorsement by the US Government.

Edited by: M. E. Contadakis

\section{References}

Beltrami, H. and Mareschal, J. C.: Ground temperature histories for central and eastern Canada from geothermal measurements: Little Ice Age signature, Geophys. Res. Lett., 19, 689-692, 1992.

Charlson, G. S. and Sani, R. L.: Thermoconvective instability in a bounded cylindrical fluid, Int. J. Heat Mass Tran., 13, 14791496, 1970.

Charlson, G. S. and Sani, R. L.: On thermoconvective instability in a bounded cylindrical fluid layer, Int. J. Heat Mass Tran., 14, 2157-2160, 1971.

Clow, G. D.: USGS Polar Temperature Logging System, Description and Measurement Uncertainties, US Geological Survey, Reston, Virginia USA, Techniques and Methods 2-E3, available at: http://pubs.usgs.gov/tm/02e03 (last access: January 2014), 24 pp., 2008.

Clow, G. D.: USGS permafrost temperatures acquired from the DOI/GTN-P Deep Borehole Array in arctic Alaska, 1973-continuing, Advanced Cooperative Arctic Data and Information Service (ACADIS), Boulder, Colorado USA, doi:10.5065/D6N014HK, 2013.

Gryc, G.: Geology and exploration of the National Petroleum Reserve in Alaska, 1974 to 1982, Professional Paper 1399, US Geological Survey, Reston, Virginia USA, 940 pp., 1988.

International Permafrost Association (IPA): IPA-IPY thermal state of permafrost (TSP) snapshot borehole inventory, National Snow and Ice Data Center, Boulder, Colorado USA, doi:10.7265/N57D2S25, 2010.

Jeffries, M. O., Richter-Menge, J., and Overland, J. E. (Eds.): Arctic Report Card 2012, available at: http://www.arctic.noaa.gov/ report12 (last access: January 2014), 2012.

Jeffries, M. O., Overland, J. E., and Perovich, D. K.: The Arctic shifts to a new normal, Phys. Today, 66, 35-40, 2013.

Lachenbruch, A. H. and Brewer, M. C.: Dissipation of the temperature effect of drilling a well in arctic Alaska, Bulletin 1083-C, US Geological Survey, Reston, Virginia USA, 73-109, 1959.

Lachenbruch, A. H. and Marshall, B. V.: Changing climate: geothermal evidence from permafrost in the Alaskan Arctic, Science, 234, 689-696, 1986.

Lachenbruch, A. H., Sass, J. H., Marshall, B. V., and Moses Jr., T. H.: Permafrost, heat flow, and the geothermal regime at Prudhoe Bay, Alaska, J. Geophys. Res., 87, 9301-9316, 1982.

Lachenbruch, A. H., Sass, J. H., Lawver, L. A., Brewer, M. C., Marshall, B. V., Munroe, R. J., Kennelly, J. P., Galanis Jr., S. P., and Moses Jr., T. H.: Temperature and depth of permafrost on the Arctic Slope of Alaska, Professional Paper 1399, US Geological Survey, Reston, Virginia USA, 645-656, 1988a.

Lachenbruch, A. H., Cladouhos, T. T., and Saltus, R. W.: Permafrost temperature and the changing climate, in: Proceedings of the 5th International Conference on Permafrost, Trondheim, Norway, 25 August 1988, vol. 3, 9-17, 1988b.

Mareschal, J. C. and Beltrami, H.: Evidence for recent warming from perturbed geothermal gradients: examples from eastern Canada, Clim. Dynam., 6, 135-153, 1992.

Nielsen, S. B. and Balling, N.: Accuracy and resolution in continuous temperature logging, Tectonophysics, 103, 1-10, 1984.

Nielsen, S. B. and Beck, A. E.: Heat flow density values and paleoclimate determined from stochastic inversion of four temperature-depth profiles from the Superior Province of the Canadian Shield, Tectonophysics, 164, 345-359, 1989.

Osterkamp, T. E. and Jorgenson, J. C.: Warming of permafrost in the Arctic National Wildlife Refuge, Alaska, Permafrost Periglac., 17, 65-69, 2006.

Osterkamp, T. E. and Romanovsky, V. E.: Evidence for warming and thawing of discontinuous permafrost in Alaska, Permafrost Periglac., 10, 17-37, 1999.

Riseborough, D. W.: Soil latent heat as a filter of the climate signal in permafrost, Proceedings of the Fifth Canadian Permafrost Conference, Collection Nordicana No. 54, Université Laval, Québec, 199-205, 1990.

Romanovsky, V. E., Smith, S. L., and Christiansen, H. H.: Permafrost thermal state in the polar Northern Hemisphere during the International Polar Year 2007-2009: a synthesis, Permafrost Periglac., 21, 106-116, 2010.

Saltus, R. W. and Clow, G. D.: Deconvolution of Continuous Borehole Temperature Logs: Algorithms and Accuracies, Open-File 
Report 94-254, US Geological Survey, Reston, Virginia USA, 42 pp., 1994.

Sass, J. H., Lachenbruch, A. H., Munroe, R. J., Greene, G. W., and Moses Jr., T. H.: Heat flow in the western United States, J. Geophys. Res., 76, 6376-6413, 1971.

Sessa, R. and Dolman, H. (Eds.): Terrestrial Essential Climate Variables for Climate Change Assessment, Mitigation and Adaption, GTOS 52, Global Terrestrial Observing System, Food and Agricultural Organization of the United Nations, Rome, 2008.

Smith, S. and Brown, J.: Assessment of the Status of the Development of the Standards for the Terrestrial Essential Climate Variables - T7 - Permafrost and Seasonally Frozen Ground, GTOS 62, Global Terrestrial Observing System, Food and Agricultural Organization of the United Nations, Rome, 2009.

Smith, S. L., Burgess, M. M., Riseborough, D., and Nixon, F. M.: Recent trends from Canadian permafrost thermal monitoring sites, Permafrost Periglac., 16, 19-30, 2005.

Smith, S. L., Romanovsky, V. E., Lewkowicz, A. G., Burn, C. R., Allard, M., Clow, G. D., Yoshikawa, K., and Throop, J.: Thermal state of permafrost in North America - a contribution to the International Polar Year, Permafrost Periglac., 21, 117-135, 2010.
Steinhart, J. S. and Hart, S. R.: Calibration curves for thermistors, Deep-Sea Res., 15, 497-503, 1968.

Strang, G. and Nguyen, T.: Wavelets and Filter Banks, WellesleyCambridge Press, Wellesley, Massachusetts USA, 1996.

Swartz, J. H.: A geothermal measuring circuit, Science, 120, 573574, 1954.

Taylor, A. E., Wang, K., Smith, S. L., Burgess, M. M., and Judge, A. S.: Canadian arctic permafrost observatories: detecting climate change through inversion of subsurface time series, J. Geophys. Res., 111, B02411, doi:10.1029/2004JB003208, 2006.

Urban, F. E. and Clow, G. D.: DOI/GTN-P climate and active-layer data acquired in the National Petroleum Reserve-Alaska and the Arctic National Wildlife Refuge, Data Series 812, US Geological Survey, Reston, Virginia USA, doi:10.3133/ds812, 2014. 